\title{
DETECTING LEARNING STYLES IN VIDEO GAMES
}

\author{
A Thesis \\ presented to \\ the Faculty of California Polytechnic State University, \\ San Luis Obispo
}

\author{
In Partial Fulfillment \\ of the Requirements for the Degree \\ Master of Science in Computer Science
}

by

Benjamin Cooley

March 2015 
(C) 2015

Benjamin Cooley ALL RIGHTS RESERVED 


\section{COMMITTEE MEMBERSHIP}

$\begin{array}{ll}\text { TITLE: } & \text { Detecting Learning Styles in Video } \\ & \text { Games }\end{array}$

AUTHOR: $\quad$ Benjamin Cooley

DATE SUBMITTED: $\quad$ March 2015

COMMITTEE CHAIR: $\quad$ Michael Haungs, Ph.D.

Professor

COMMITTEE MEMBER: Foaad Khosmood, Ph.D.

Assistant Professor

COMMITTEe MEMBER: Phillip Nico, Ph.D.

Professor 


\section{ABSTRACT \\ Detecting Learning Styles in Video Games}

Benjamin Cooley

Video games are increasingly becoming more intelligent, able to adapt themselves to the individual gamer. Learning styles are a set of models used to categorize people into different types of learners to explain why some people learn better through different methods. Since learning and exploration are such fundamental parts of the video game experience, it is interesting to consider the possibility of applying these learning style models to video games, allowing the video game to adapt to its player, providing a better experience. To consider such adaptation, the game must first be able to detect that learning style from how the player has interacted with it.

Simple metrics collected during game play of an instrumented game (opensource Supertux) are compared to the results of the Hay Group's Kolb Learning Style Inventory, a paper test designed to determine one's learning style. A relationship between recordable game play metrics and the academic model for learning would allow a game designer to potentially infer that model from game play and use it to adapt the game to that type of learner. 
LIST OF TABLES . . . . . . . . . . . . . . . . . . . . . . . . . . vii

LIST OF FIGURES . . . . . . . . . . . . . . . . . . . . . . . . . viii CHAPTER

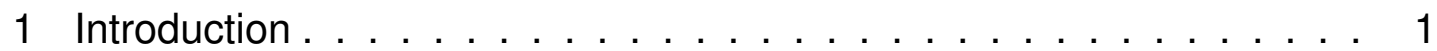

1.1 Learning Styles . . . . . . . . . . . . . . . . . . . . . 3

1.2 Gaming Metrics . . . . . . . . . . . . . . . 5

2 Related Work . . . . . . . . . . . . . . . . . . . . . . . 8

2.1 Learning through Games $\ldots \ldots \ldots \ldots$

2.2 Adaptiveness . . . . . . . . . . . . . . . . . . . . 9

2.3 Learning styles . . . . . . . . . . . . . . . . 10

3 Experiment. . . . . . . . . . . . . . . . 13

3.1 Kolb . . . . . . . . . . . . . . . . . . 13

3.1.1 Kolb Learning Styles . . . . . . . . . . . . . . . 15

3.1.2 Learning Style Inventory (LSI) . . . . . . . . . 16

3.2 The Game (Supertux) ․ . . . . . . . . . . . . . . . . 17

3.3 Methodology . . . . . . . . . . . . . . . . . 19

4 Results . . . . . . . . . . . . . . . . . . . . . . 21

4.1 LSI (Paper Test) . . . . . . . . . . . . . . . . . . . . . 22

4.2 Game (Event Log) . . . . . . . . . . . . . . . . . . . . 24

4.2.1 Evaluating Possible Groupings . . . . . . . . . . . . 25

4.3 Analysis . . . . . . . . . . . . . . . . 26

4.3.1 Completion . . . . . . . . . . . . . . . . 27

4.3.2 Unique Kill Methods . . . . . . . . . . . . . . . . . . 28

4.3.3 Other Groupings . . . . . . . . . . . . . . . . . . . . . . . . . 29

4.3.4 Combinations of Groups . . . . . . . . . . . . . . . . 30

4.4 Summation . . . . . . . . . . . . . . . . . . . 30 
5 Future Work . . . . . . . . . . . . . . . . . . 32

6 Conclusion . . . . . . . . . . . . . . . . . . . 34

BIBLIOGRAPHY . . . . . . . . . . . . . . . . . 35 APPENDICES

APPENDIX A Experiment Design . . . . . . . . . . . 38

APPENDIX B Experiment Results . . . . . . . . . . . . . . 40

B.1 LSI (Paper Test) . . . . . . . . . . . . . . . . . . . . 40

B.2 Game Test Results . . . . . . . . . . . . . . . . . . . . . . . 41

B.2.1 Sample Raw Event Data . . . . . . . . . . . . . 41

B.2.2 Sample Analysis/Aggregated output . . . . . . . . 43

B.3 Aggregated Data . . . . . . . . . . . . . . . . . 51

APPENDIX C Analysis. . . . . . . . . . . . . . . . 52

C.1 Classifier Output . . . . . . . . . . . . . . . . . . 54 


\section{LIST OF TABLES}

Table

Page

Table 4.1 LSI Groupings . . . . . . . . . . . . . . . . . . . . . 23

Table A.1 List of Recorded Events . . . . . . . . . . . . . . . . . . 38

Table B.1 Learning Style Test Results . . . . . . . . . . . . . . . . 40

Table B.2 Aggregated Data . . . . . . . . . . . . . . . . . 51

Table C.1 Participant Groupings . . . . . . . . . . . . . . . . . . 52 


\section{LIST OF FIGURES}

Figure

Page

Figure 3.1 Kolb's Experiential Learning. From Experiential Learning: Experience as the Source of Learning and Development . . 14

Figure 3.2 Platformer Screenshot: A platformer is a game the player navigates through a level, avoiding obstacles to reach an objective. 17

Figure 3.3 Supertux Screenshot: A screenshot from Supertux that shows several of the game elements recorded. . . . . . . . . 18

Figure 4.1 Results of paper LSI test . . . . . . . . . . . . . . . . 22

Figure 4.2 Unique Enemies Killed: Participants results evaluated against the criteria of Unique Enemies Killed, Sorted. . . . . . . 26

Figure 4.3 Completion vs Learning Styles $\ldots \ldots$. . . . . . . . 27

Figure 4.4 Unique Kills as Percentage . . . . . . . . . . . . . 28

Figure 4.5 Unique Coins Collected: Participants results evaluated against the criteria of Unique Coins Collected, Sorted. . . . . . . 31 


\section{CHAPTER 1}

Introduction

Interactive video games are deeply seeded in the process of learning. This is built into the very interactive nature of these games. A story-based game will heavily utilize learning-by-discovery to allow their user to interactively uncover the story or challenge. A game of skill will expect users to learn strategies and hone game play skills to master its mechanics. Modern commercial video games are extremely complex systems that need to quickly acclimate their users to their rules so they can immerse them in the game play. The learning process is itself a component of what makes games enjoyable, with many games slowly introducing rule changes throughout the entire game to keep the user learning steadily more complex and interesting game play mechanics.

However, learning is a hard process, and learners can easily be frustrated by their lack of knowledge in the area they are trying to learn. Luckily, games (and in particular, video games) are known to be highly motivating, helping players push themselves through the process[7, 15]. The desire to win, reach game rewards, or even just to keep playing will keep players trying the challenges again and again. The achievement of the skills of the game is itself rewarding, contributing to the reward of completing a challenge. This motivation (or engagement or enthusiasm) is very powerful, enough to make it worth using games to teach other topics[4,5]. Educational games try to harness this motivation to help students learn real-world topics such as math or science.

Of course, this process could easily fail if a challenge is too hard or the 
player does not recognize the incremental progress they are making toward the challenge, they may give up and stop playing entirely. Thus learning can be a double-edged sword: Give a player a new tool and they may master it and enjoy the process; but if they are unable to understand or learn the new tool they could get frustrated and stop playing.

It is interesting to consider applying research on learning to video games. In particular, examining how different types of learners interact with games. These learning styles assessments are ways to label people based on how they learn. Generally with the idea that some people are better at learning certain ways over others. Since learning is both an integral part of the enjoyment of games and an area that could easily break the user away from such enjoyment, applying these assessments could allow better integration into the learning experience into the game. Well-designed video games already support many different learning styles, allowing players to approach problems in a way of their choosing.[1] If game designers knew the learning style of the player, they could customize content for that player, instead of the player picking from multiple paths. They might use this to shorten the initial learning curve of the game or tutorial, reduce (or increase) game difficulty, or better integrate educational content. Even excluding customized content, learner information could be used to better understand a game's players, or perhaps help identify what kinds of new players could be targeted.

The idea of adapting a game to a player's learning style can be split into two questions: How might a game designer discover what is the learning type of their player, and what might they do with this information once they have it. This thesis examines the first question, explicitly, is there a correlation between how the player plays the game and their learning style. Finding that cor- 
relation between learning styles and the player's in-game performance would allow the game to determine (or at least estimate) the player's learning style. Thus, opening avenues for improvements on the player's session by tailoring the player experience to their learning style.

To find potential correlations, there are two datasets to examine. First, one of the many taxonomies of 'learning styles' is selected. It is important the taxonomy selected is widely accepted and has a reliable method for assessment. Second, data might be reasonably collected on player performance and decision-making.

A experiment was designed for a group of participants to play an instrumented video game and take a standard learning assessment test. Correlation between game play and learning style was sought. The results were examined to see if the data gathered from the instrumented video game is at all related to the output of the learning assessment test.

\subsection{Learning Styles}

Learning styles model ways to classify and assess the differences in how people learn. Numerous models of learning styles have been put forward. An extensive (but not exhaustive) literature review by Coffield, et al[3] identified 71 models. None of these models has found a high enough acceptance in theory or practice to be considered a de-facto standard. The idea that people learn differently (faster and/or better with different processes) and that it can be classified has a lot of intuitive appeal. In the simplest models, learning styles can be thought of as a simple division of the spectrum of learners. In these models, learners fall into distinct learning subdivisions, where one expects certain 
learning experiences to resonate better with one group over another.

One of the most widely used models is Neil Fleming's VAK[11], a easy to understand model that amply demonstrates the notion of learning styles. VAK sorts learners into three categories: Visual, Auditory and Kinesthetic learning styles. A visual learner will perform better when given visual aids, such as slides or handouts. An auditory learner performs best with auditory material, like lectures or tapes. A kinesthetic learner performs best with hands-on exploration and experimentation based learning.

Many models, including VAK, do not translate well into game learning. They are generally designed around the notions of classroom learning (or 'book learning') which is a very different type of learning than you see in a video game. These models might be mappable to video games, but there would be problems related to the fundamental difference between classroom learning and leisurely game play. After all, video games are interactive, so almost every experience will contain 'hands-on exploration and experimentation'.

Another major learning style model is Kolb's Experiential Learning Model[6]. Kolb's model is based on the process of experiential learning. Experiential learning is the type of learning that you gain from personal experience in the subject. This type of learning is defined less by pure information absorption and more with total cumulative exposure to the material. The more experience you have learning a particular subject, the greater depth you have in that subject. This is the type of learning that would be found in video games. While it is possible to 'study' game play strategy, most game skills come from having a wealth of previous experiences to draw upon. To address these concerns, Kolb's model is used as our learning assessment tool. 
Kolb's Experiential Learning Model breaks the learning process into four stages. It then measures how proficient the learner is at each of these stages. These stages are always required as part of the learning process, but learners can be better at one over another. The result is then plotted on a twodimensional graph. Kolb's learning style is then defined by which quadrant of the graph the learner falls into.

Kolb put forth this model in his book Experiential Learning: Experience as the Source of Learning and Development[10]. The assessment for the learning model and the derivative learning style is now provided commercially from the Hay Group. This test is used for the assessment of learning styles in this experiment.

\subsection{Gaming Metrics}

There are many metrics that can be gathered during game play. These metrics might be useful in predicting a players learning style. The focus is specifically on gaming metrics, or the measurable data that a game might determine itself while the player is playing. This is data that can be collected in the background of the game about how the player is interacting with it, without adding additional design requirements.

There are other types of data that could be collected from game play and possibly be useful in predicting a players learning style. Observational data could be recorded, such as the judgments of a third party watching the game player. Another option would be to take external data, such as requesting feedback from the user outside of game play (How did you feel you did on this level?). The design could also be changed to help improve the metrics: 
information on whether a player completes a challenge may be more useful if the challenge is designed to encompass one style of learning.

Basic gaming metrics were used for this experiment because they are the most useful in making an automated and dynamic determination of their learning style. Dynamic determination of learning style would be preferred, as it would allow the game to customize its contents based on that dynamic data. This is not to say one would not be able to use the other types of data in this way, one could imagine a pre-game test or profile data stored in some external system. Game metrics are just the simplest to instrument and collect. It requires the least additional design/process work to be incorporated into the game, as it can be handled entirely in the background. This data would be available universally (as all games have player choices by definition) without performing extra design work, and many times it is already gathered for a leader-board/achievement system.

Which gaming metrics are available is unique to the type of game in question. A puzzle game has information available on time spent on different parts of the puzzles, how long the user contemplated the entire puzzle before starting it and so on. A platform game (a genre where an on-screen avatar navigates between multiple stand-alone platforms and obstacles) has information on how the player attempts to interact with the map. This data includes where they die or what platforms or enemies they hit. A fighting game has information on the types of offensive and defensive button combinations the player uses.

The above mentioned metrics are game-specific versions of player responses. In particular, given a specific game play challenge and the limited in-game options the player has at their disposal, what actions did the player take. Trends toward one particular strategy over another could be related to how players 
learn. One player may pick combat, another might pick exploration, and yet another might seek the fastest solution. In addition to looking at player responses, meta-level information about their responses can also be considered. The order of strategies can be related, such as one group of players starting out exploring but then migrating to combat.

The game chosen for this experiment is a side-scrolling platformer. This is a game where the player avatar has to move right across a 'scrolling' field of view, jumping between platforms to reach the end of the scroll (or goal). The player must avoid obstacles and may collect rewards. The data available is related to what objects the player interacts with on the screen, how they interact or avoid enemies, and which collectibles are gathered. 


\section{CHAPTER 2}

Related Work

This thesis straddles multiple domains. There is only a very limited set of work relating to applying learning styles to video games. In order to provide background, relevant work from the related domains: Educational games, Adaptive games and Learning styles.

\subsection{Learning through Games}

The question of what kind of learning happens in games has been looked at extensively. In particular, the question is viewed through the lens of trying to harness the learning processes in games to use toward more traditional educational goals.

What Makes Things Fun to Learn? Heuristics for Designing Instructional Computer Games[12]: A seminal work on learning in video games, Malone discusses the ability of video games to keep players playing even in the face of challenges. Malone describes games are intrinsically motivating, an activity that itself motivates the learner to continue, in comparison to extrinsically motivated learning, where the learner completes in pursuit of an external goal or reward.

The invention of good games: understanding learning design in commercial video game[2]: An extensive comprehensive recent work on learning in commercial games. Becker examines how the entire spectrum of learning 
applies back to commercial video games. Becker ties together works across many different fields to examine the question of the state of learning in commercial video games. Of particular interest is her investigation of applying learning styles to games (partially reproduced in her 2005 publication, Games and Learning Styles[1]). Becker examines different learning style models and how the styles that are defined in each model might map back to player behavior.

Learning by Design: good video games as learning machines, ELearning[7]: An article that explains the importance of learning in modern games and examines how game designers choose design patterns that facilitate that learning. Focus is on the incredible complexity that exists in modern games and must be taught to the user in order for them to play.

Pervasive learning games: Explorations of hybrid educational gamescapes[16]:

Thomas examines the types of learning that takes place in pervasive games, such as second life. An interesting example of examining learning for a particular type of game, showing that one model might not easily be applied to all video games.

\subsection{Adaptiveness}

Adaptive games describes video games that dynamically update themselves based on what they know about the player's past performance. Of particular interest are works related to adapting information on how the player learns, as opposed to other possible indicators (such as skill level). Like the works studying learning in games, the works studying adapting to learning are largely focused on educational games. However, they provide good context for looking 
at adaptive learning in entertainment games.

Adaptive Support For Student Learning in Educational Games[17]: An experiment about adapting a 'tutorial' in a simple game to adjust to the players knowledge. Zhao looks at building a knowledge net based on what the player has previously accomplished to recognize which areas the player has not yet mastered and allow the tutorial helper to focus hints on those areas.

80Days: Melding Adaptive Educational Technology and Adaptive and Interactive Storytelling in Digital Educational Games[8]: A look at adapting a particular education game to the type of learner. The focus is on providing multiple learning experiences (games) that can cover the same educational material in different ways. The learner can then be focused on the methods that are most effective for them.

Providing Non-invasive Personalized Learning Experiences[14]: A look at incorporating educational material into games non-invasively. Peirce et al. investigates how games with educational content can be made to feel more like games and less like playing through a schoolbook by adapting to the player. Many variables are mentioned as possible triggers that the games could adapt to, including the notion of Learning Styles.

\subsection{Learning styles}

Learning styles has an incredibly wide base of research to draw on, although the work is scattered across many different learning style models.

Learning styles and pedagogy in post-16 learning: A systematic and critical review[3]: Survey of literature in Learning styles. A total of seventyone different methods were identified, sorted into 6 different families. Thirteen 
of the major models were reviewed in detail.

Experiential Learning: Experience as the Source of Learning and Development[10]: Examines experiential learning as a major non-classroom based learning experience. Focuses largely on adult experience-based learning, drawing contrast to some other well examined learning systems, such as mimicry and classroom learning. Also defines the notion of learning styles (including several experiments) that was later expanded into the commercial Kolb Learning Style Inventory.

The Kolb Learning Style Inventory - Version 3 - 12005 Technical Specifications, Education[9]: The technical specifications of the Kolb Learning Style Inventory, including many reference charts and examples about how baseline populations have done when taking the test.

Attempted Validation of the Scores of the VARK: Learning Styles Inventory With Multitrait-Multimethod Confirmatory Factor Analysis Models, Educational and Psychological Measurement[11]: A detailed look into the VARK learning model, one of the most commonly used learning style systems.

JISC e-Learning Models Desk Study Stage 2 : Review of e-learning theories, frameworks and models, Learning[6]: A review of the application of learning styles to e-learning. The idea is to apply different e-learning models based on the type of learner that is using the system.

Learning styles concepts and evidence[13]: An examination of the practical uses of Learning Styles. Pashler et al. examines the evidence (or lack thereof) supporting learning styles, the availability of practical tests for learning styles and the uses of learning styles once they have been determined. 
Though widely studied, the learning style notion has little field application. 


\title{
CHAPTER 3
}

\author{
Experiment
}

\subsection{Kolb}

Kolb's Model of experiential learning is built on the concept of a learning cycle. It was defined in Experiential Learning: Experience as the Source of Learning and Development[10]. There are four stages, and a learner must use every stage during the learning experience. The process of learning through experience progresses through these stages. At any one time, a learner may be using any number of the stages, or none at all. The stages are defined in Figure 3.1.

Kolb Learning Stages:

- Concrete Experience: The learner experiences the event, or is 'feeling' it. This is where a learner get wrapped up in the moment, and is the foundation the other stages draw upon.

- Reflective Observation: The learner reflects on the event, or is 'watching' it. This is where a learner try to put the events into words, creating an understanding of what happened.

- Abstract Conceptualization: The learner abstracts the events, or is 'thinking' about it. This is where a learner build tries to create (or update) a model for what is happening.

- Active Experimentation: The learner changes the event, or takes action. 


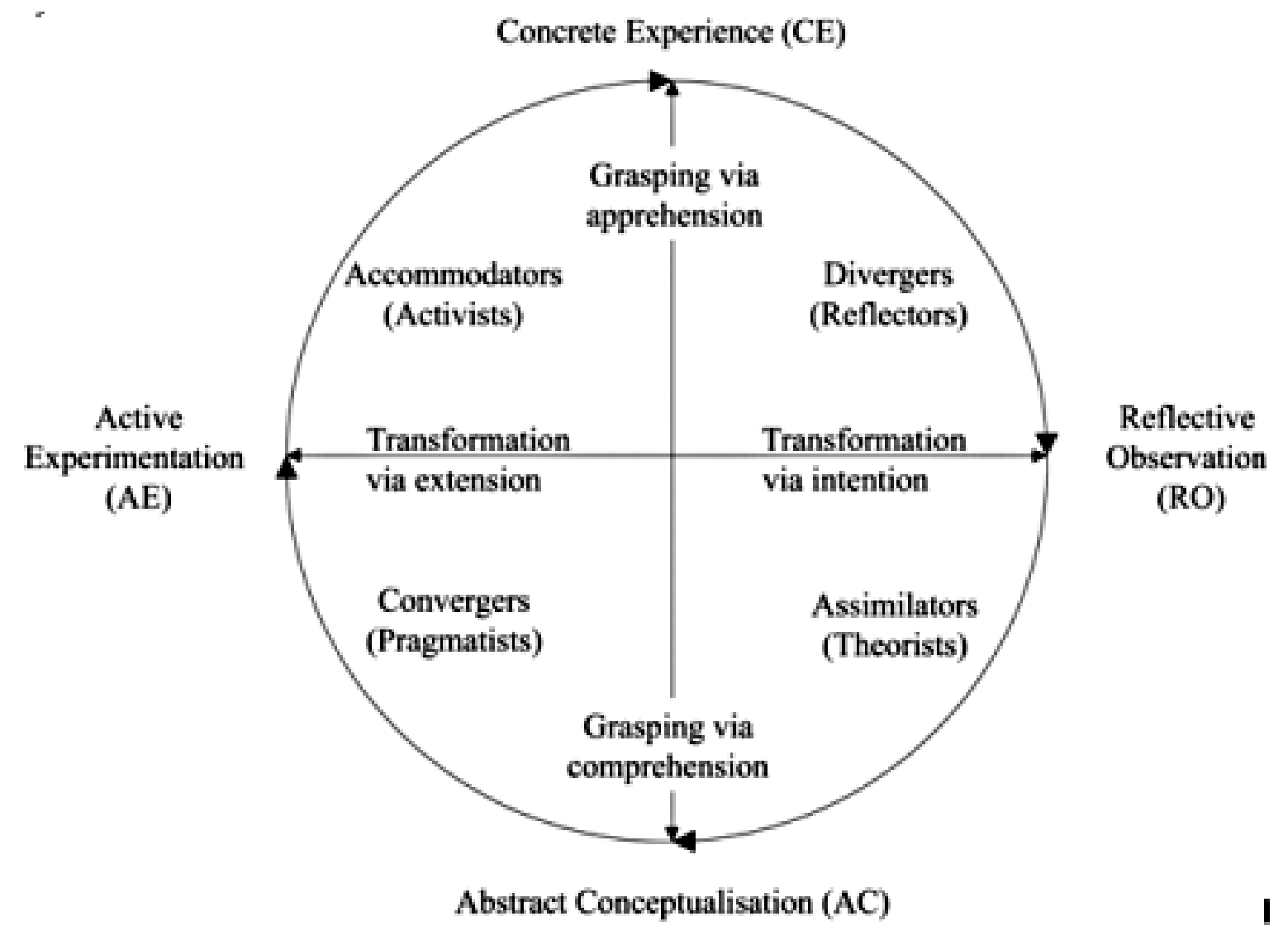

Figure 3.1: Kolb's Experiential Learning. From Experiential Learning: Experience as the Source of Learning and Development[10] 
This is the last link in the feedback loop, the learner changing the event based on what they have learned so far.

Information is first found through experience, then reflected upon and abstracted, and finally turned into action that changes the experience. These stages fall on the Transformation and Grasping Axes. Reflective Observation and Active Experimentation transform the event into something else, while Concrete Experience and Abstract Conceptualization grasp an understanding of the event.

\subsubsection{Kolb Learning Styles}

As learners process an experience, they cycle through the stages, each in their own unique order and time. This causes learners to have their own unique style of learning, with the styles being defined by how heavily they favor any individual stage. Ideally, every learner would be as good as any one of the learning stages as the rest. This would allow the learner to have the most efficient process, moving information through the cycle. However, learners tend to prefer certain parts of the cycle over others. The stages along the axis's are negatively correlated, so that learners who prefer one state tend to avoid the stage on the other side of the axis. This means that most learners end up with two stages they are better at, and two which they are not, one from each axis.

This does not mean these learners are exclusive to their learning style. Every learner must go through all stages of the cycle. The learning style does tend to indicate which part of the cycle they start a problem on, and which areas they spend most of their time on. Graphically, the 'Learning Style' is the 
quadrant you fall under on the chart.

Accommodative Learner $\mathrm{AE}+\mathrm{CE}$ : This type of learner likes to try things and experiment. They will likely develop an intuitive feel about what is right and use that as the basis for their decisions.

Divergent Learner CE + RO: This type of learner likes to watch. They will watch experiences and try to internalize them, or spend time reflecting the observed experience.

Assimilator Learner $\mathrm{RO}+\mathrm{AC}$ : This type of learner likes to comprehend. They will likely relate the experience to other experiences in their life.

Convergent Learner $A C+A E$ : This type of learner likes to build models. They will form a model of the problem in their head, and experiment with it till they get it right.

\subsubsection{Learning Style Inventory (LSI)}

The LSI is a paper test maintained by the Hay group to allow people to evaluate for their learning style. This produces four distinct scores (One for AE, CE, $R O$, and $A C$ ), two aggregate scores ( $A E-R O$ and $A C-C E)$, which define the 'quadrant' on the chart, and therefore the learning style. 


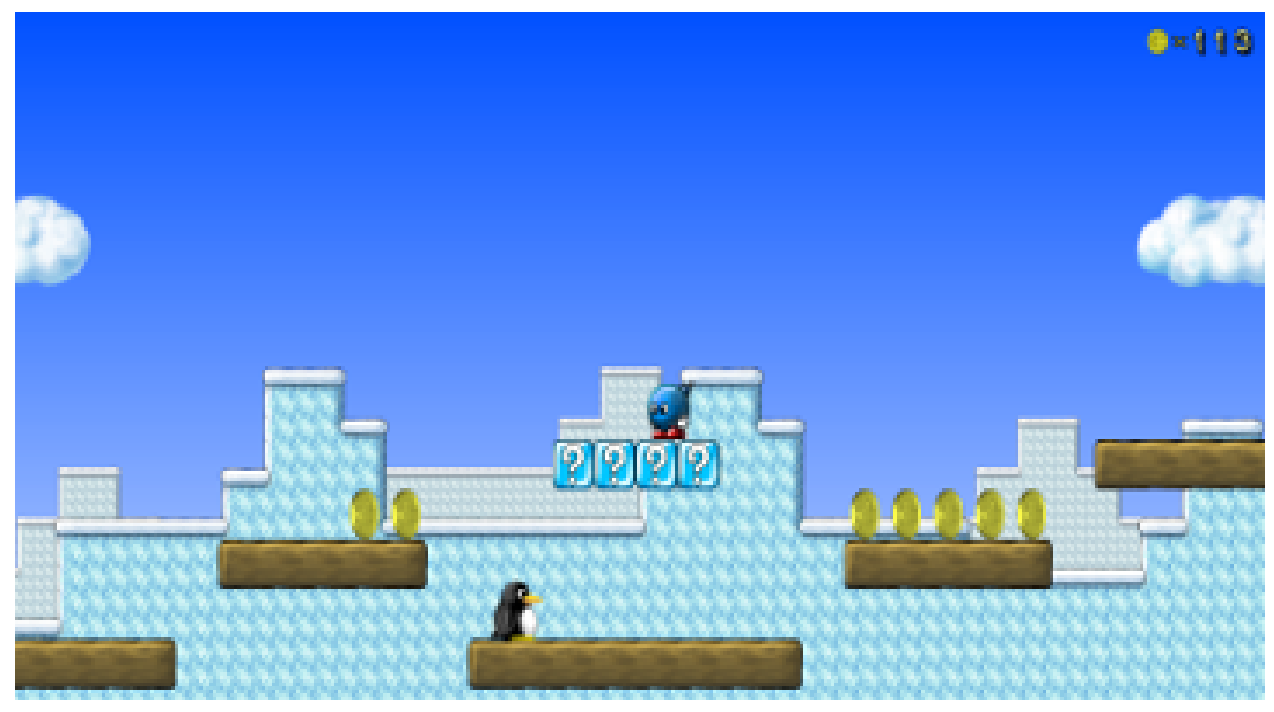

Figure 3.2: Platformer Screenshot: A platformer is a game the player navigates through a level, avoiding obstacles to reach an objective.

\subsection{The Game (Supertux)}

Supertux is an Open Source game in the style of the 'Super Mario Brothers' games. Supertux is a simple side-scrolling platformer with a limited control scheme (limited user inputs). Side-scrolling platformers have been popular commercially since Super Mario Brothers popularized the genre in 1985. The genre is seeing new major commercial releases every year. A majority of Supertux's game play is either jumping on or avoiding enemies while progressing to the right of the screen. The goal of the game is to get to a goal post at the end of the level, possibly interacting with the level and collecting coins and upgrades along the way. See Figure 3.2

Supertux was modified to record data about how the user played. The recorded data included a heartbeat (player location every few seconds) as well as a record for every significant event (such as death or coin collected). See Appendix Table A.1, a list of what was instrumented. The game was also 


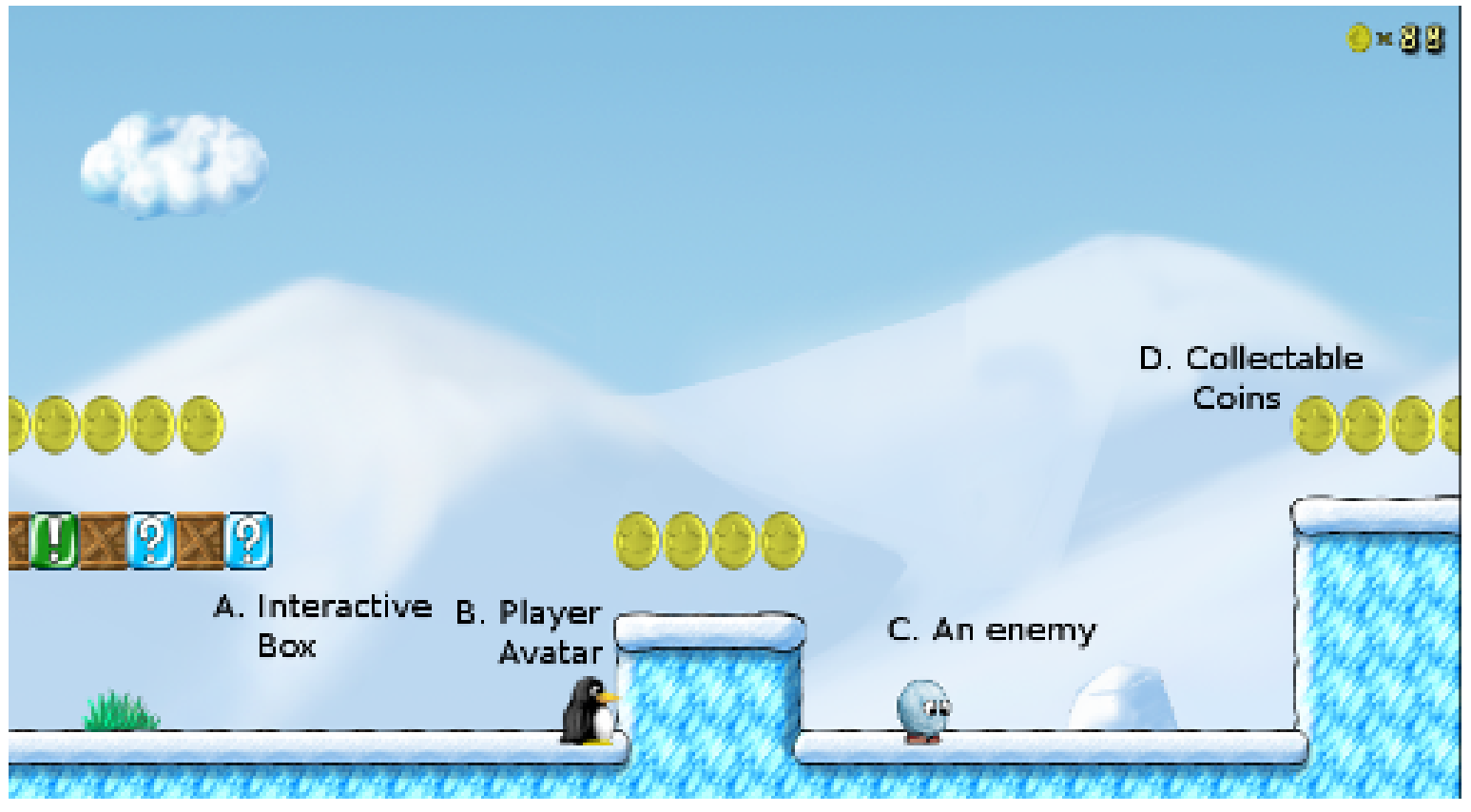

Figure 3.3: Supertux Screenshot: A screenshot from Supertux that shows several of the game elements recorded.

modified to only provide a single level, simplifying the player experience and data collected.

Figure 3.3, shows several of the elements that instrumented:

A: Interactive Box: These boxes are interactive such that if the player hits them from below a reward will pop out.

B: Player Avatar: The player avatar is instrumented with a heartbeat, recording where it is every five seconds. Significant events to the player avatar (such as death) were also recorded.

C: An Enemy: Enemies provide the player with a challenge they must avoid or defeat. This particular enemy kills the player on a side collision, but is killed on a above collision.

D: Collectable Coins: As the player collects coins, the counter at the top right 
of the screen increases.

Supertux has a half-dozen different enemy types available, along with a single type of collectible (a coin). Controls are simple, arrow keys for movement, along with Space for jump and Ctrl for "special". Dying in the game resets the player to the beginning of the level, allowing the player to experiment with different strategies.

\subsection{Methodology}

The experiment was administered on an individual basis. Each participant was given an instruction sheet and seated at a computer running the instrumented game. The instruction sheet defined the control keys (which keys were valid input, not what those keys did) and asked them to play until they grew tired of the game or completed the level. If they got bored, they were asked to try to complete at least five minutes of game play to provide an adequate sample. When the participant finished playing, they were given a paper version of the Learning Style Inventory.

The participants were 23 volunteers. Most were young professionals working in the computer science field. Many indicated that they had previous gaming experience with the type of game we were using(platformer), but we did not request or record that information.

We attempted to administer the experiment in an environment that was not time intensive nor mandatory. This was to allow volunteers to participant outside of peer pressure (like in a classroom) or artificial deadlines. The experiment had no hard time limit, allowing participants take as long as they liked. The instructions included a request for participants to spend at least five min- 
utes on the game portion of the experiment to ensure an adequate amount of data. 


\section{CHAPTER 4}

Results

The experiment generated two distict data sets; the results of the paperbased LSI test and the recorded event-stream of the game. The goal is to determine which pieces of data (if any) collected while observing game play might be useful in determining or estimating what the player would have scored on the paper-based LSI test. To do this, we compare the two data sets looking for correlations between the data collected during game play and the outcomes of the LSI test.

In order to determine which common basis should be used to compare these two data sets, we break down each set individually by sorting the participants into different groupings within that set. For example, the LSI test results can divide participants into four groups (accommodator $[A E+C E]$, reflector $[C E+R O]$, converger $[R O+A C]$ and assimilator $[A C+A E])$. This gives us a common mechanism (subsets of the participants in the group) that can be used to directly compare the results between the data sets.

For instance, if the set of people who scored 'accommodator' on the paper test also went out of their way to collect coins, total coin collection is a field that might be useful in predicting an accommodator type. We cannot necessarily say a direct causal link is necessarily the cause of these correlations. Starting with no notion of which types of data might be related to learning, simply limiting the types of data that might be useful becomes the goal. Finding correlations in certain data types allows future work to focus on expanding and 


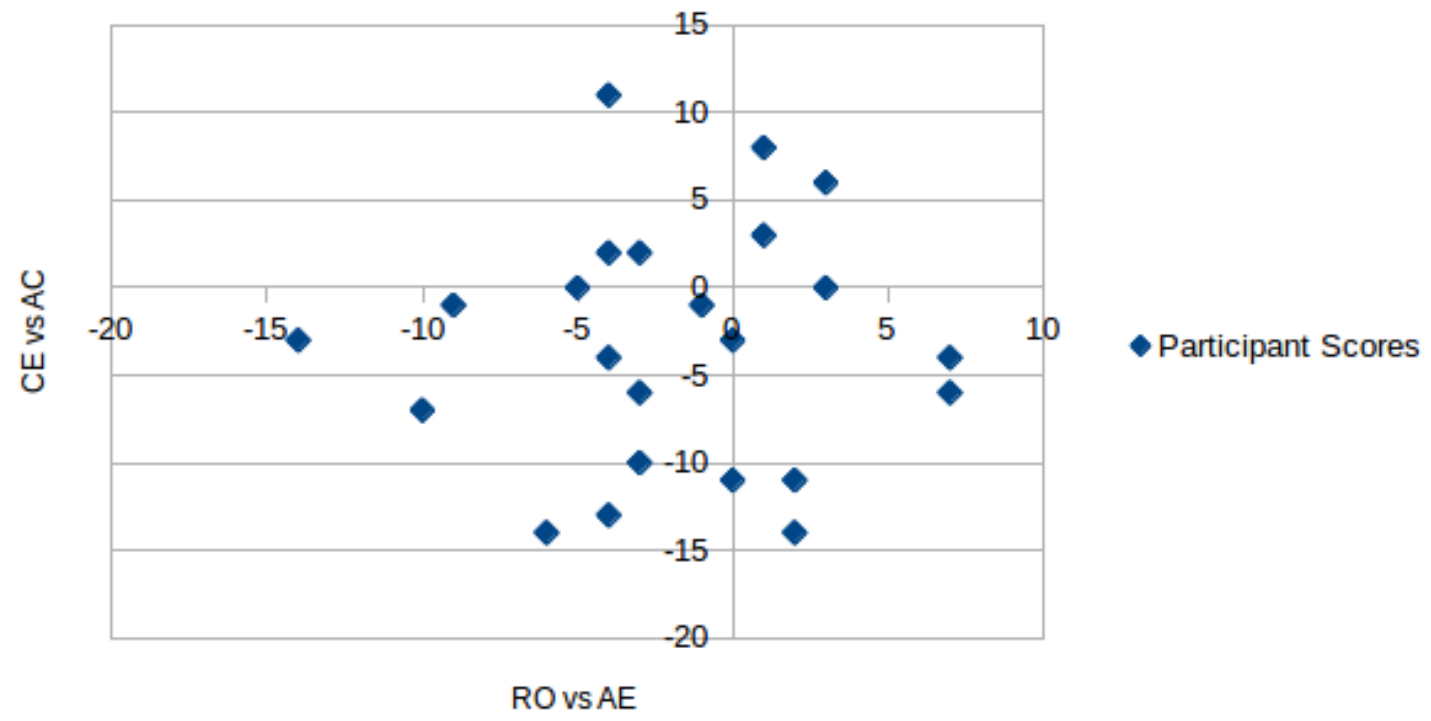

Figure 4.1: Results of paper LSI test

evaluating the link between those specific data types and the LSI results.

\subsection{LSI (Paper Test)}

The results of the paper test were essentially a pair of coordinates. One indicates where the participant is on the sliding scale of reflection versus experimentation. The other, along the scale of experimentation versus conceptualization. Figure 4.1 shows the results of the paper-based test in graphical form, Appendix B.1 shows the raw results of each participant's LSI results.

Our participant set was tilted toward the Convergers (lower left) quadrants, with a scattering of members of other quadrants. This was expected as the homogeneous pool of participants we drew upon was tilted toward the (analytical) computer sciences.

To group the data for comparison, the most straightforward mechanism is 


\begin{tabular}{|c|c|c|}
\hline Group Name & Description & Groups (Members) \\
\hline Learning Styles & $\begin{array}{l}\text { Four Groups. Based } \\
\text { on the Kolb Learning } \\
\text { Style Quadrant of the } \\
\text { participants LSI } \\
\text { results. Participants } \\
\text { who landed on the axis } \\
\text { removed. }\end{array}$ & $\begin{array}{c}\text { Accommodators (4), } \\
\text { Divergers (3), } \\
\text { Assimulators (3), } \\
\text { Convergers (9) }\end{array}$ \\
\hline $\begin{array}{c}\text { RO vs AE Axis } \\
(X \text { axis })\end{array}$ & $\begin{array}{l}\text { Categorized by score } \\
\text { along the RO vs AE } \\
\text { Axis. Split into Strong } \\
(10+) \text { Weak (1-9) and } \\
\text { Neutral (0) }\end{array}$ & $\begin{array}{l}\text { Strong RO (1), } \\
\text { Weak RO (5), } \\
\text { Neutral (2), } \\
\text { Weak AE (9), } \\
\text { Strong AE (7) }\end{array}$ \\
\hline $\begin{array}{c}\text { CE vs AC Axis } \\
\text { (Y axis })\end{array}$ & $\begin{array}{l}\text { Categorized by score } \\
\text { along the CE vs AC } \\
\text { Axis. Split into Strong } \\
(10+) \text { Weak (1-9) and } \\
\text { Neutral (0) }\end{array}$ & $\begin{array}{l}\text { Strong CE (0), } \\
\text { Weak CE (7), } \\
\text { Neutral (2), } \\
\text { Weak AC (10), } \\
\text { Strong AE (2) }\end{array}$ \\
\hline
\end{tabular}

Table 4.1: LSI Groupings 
the resulting 'learning style' (or quadrant) of the participant. Since the eventual goal is to determine the learning style from game play, a direct link between the actions players take in the game and what style they fall under would be most productive.

As an alternative, we could also consider looking at more indirect groupings, such as where a participant falls under a single axis. If data from the game matches up with the ' $x$ ' and ' $y$ ' axis, one could still derive a learning style group from that. We list how the groups break down in Table 4.1.

\subsection{Game (Event Log)}

The game results are a stream of recorded events that happened while the participate was playing the game (Section 3.2). The raw output is too large to reproduce in its entirety here, but a sample output with explanation is in Appendix B.2.

Not knowing exactly what type of data would be useful to collect, a large metric collection net was cast. This means that unlike the LSI, which produces a rather simple targeted set of data, there was a more diffuse set of data with many but less intuitive ways to group participants. Many possible data-points were recorded raising the possibility that one of them lines up with the above LSI's groups.

In order to find groupings to evaluate, the metrics were examined to see if there was any natural groupings in the data. For example, coin collection might be expected to separate players into at least two different groupings. One group who ignored coins and just proceeded through the level, collecting only what coins were incidental to their travel. The other group went out of their 
way to collect the coins they saw on the screen and even look for hidden coins. The data on coin collection, such as how many were collected or where they were collected, may show natural 'clumps' that can be refined into groupings.

\subsubsection{Evaluating Possible Groupings}

In order to find potential groupings, participants results were mapped against various criteria. With such a wide selection of recorded data, there were many possible criteria to select from. After plotting a potential criteria, it was only be used if clear groupings were indicated. When plotting the criteria, the data could be too linear (failing to produce clear groupings of participants). For instance, this was the case when looking at the number of unique enemies killed (Figure 4.2). Unique enemies killed was defined as the total number of enemies that were killed at least once over all avatar lives. There was a bit of clumping at the high end of the scale, but at the low end the results were mostly linear, with no clear grouping standing out.

It is also possible for a criteria to exclude a large portion of participants. Groupings based on those criteria resulting in such a small data set that they are not worth exploring. For example, this was the case when duration of play was examined. Duration of play is the real time taken by the participant while playing the game. This duration is fundamentally different between the people who gave up without finishing the level and those who session ended when the level was complete. As participants were split about evenly between those two options, looking at either one would result in a halved data set, greatly reducing the ability to link those groupings back to learning styles.

Criteria that was evaluated but did not produce groupings include the to- 


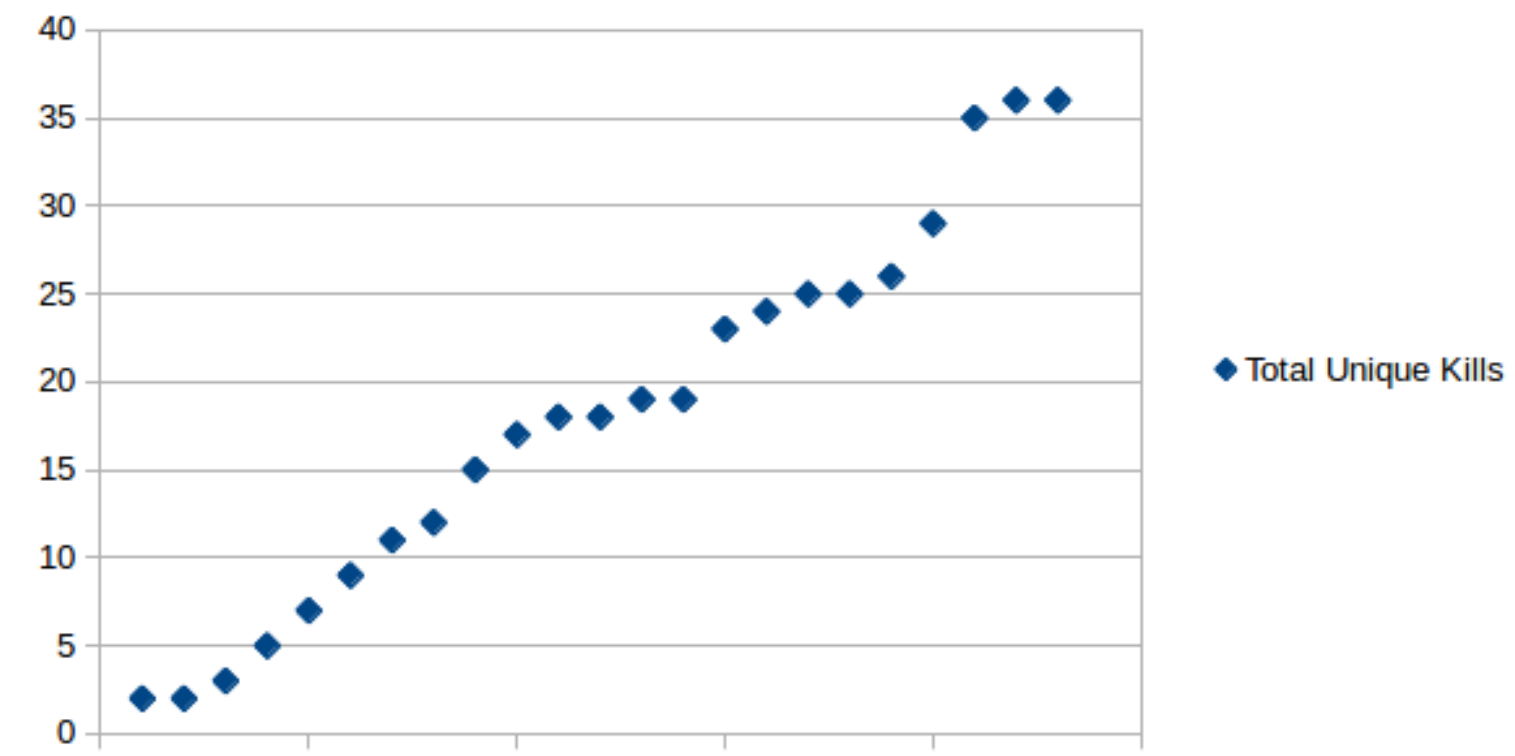

Figure 4.2: Unique Enemies Killed: Participants results evaluated against the criteria of Unique Enemies Killed, Sorted.

tal time playing (persistance), number of lives used, how many coins were collected, time taken, total number of kills and how many times the player changed direction. Aggregate criteria, such as per life and per minute (the rate of play), were also considered.

Appendix Table C. 1 shows the criteria that formed clear and interesting groups on a per-participant basis.

\subsection{Analysis}

After deriving the groupings from the game play and the paper test, correlations between the sets were explored. Since the groupings from the game may or may not be relevant, Each game grouping is examined individually and compared back to the learning style derived from the paper test. 


\subsubsection{Completion}

The participants were divided into three categories based on game completion: those who finished the game, those who got past the halfway point, and those who did not make it to the halfway point.

Learning Styles

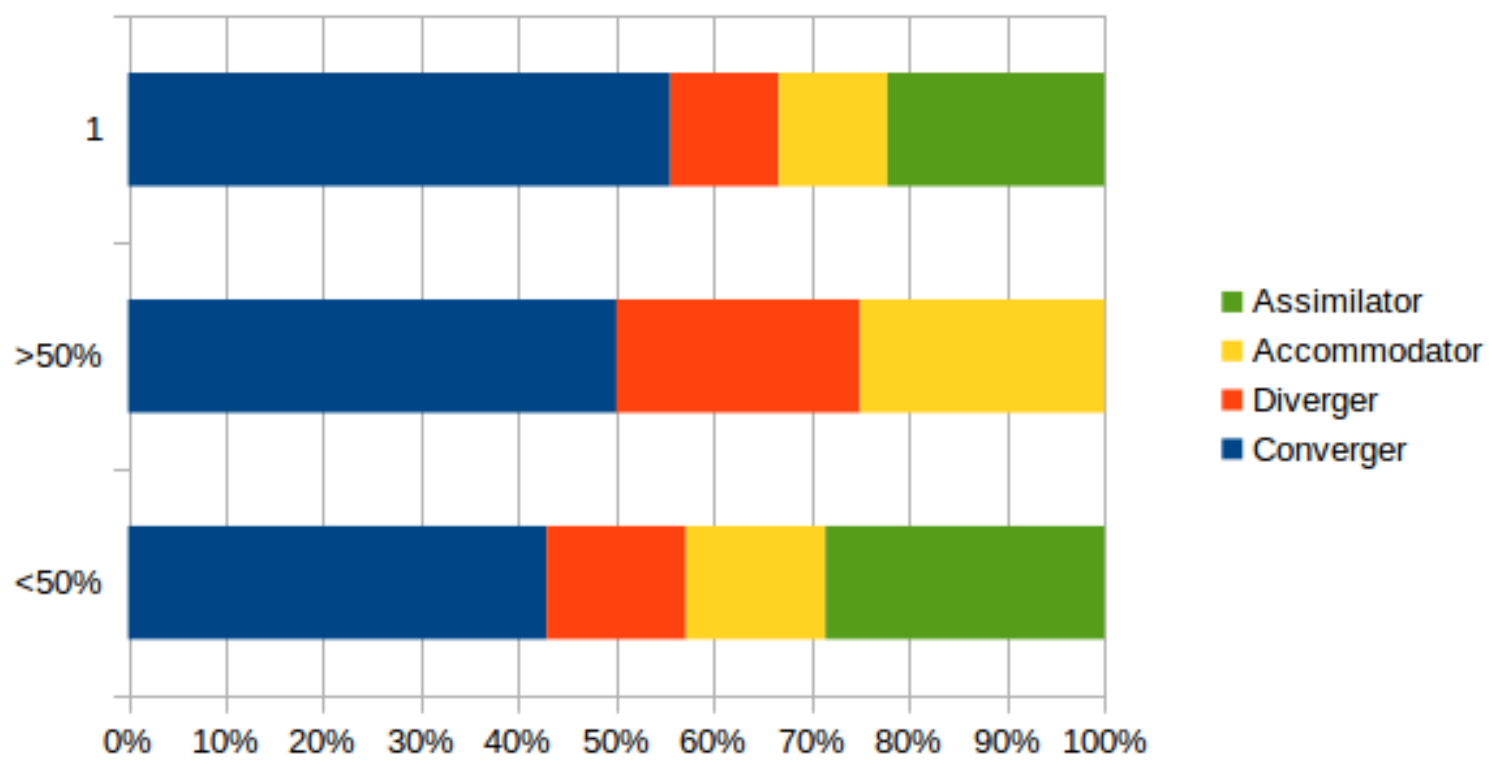

Figure 4.3: Completion vs Learning Styles

When comparing completion to learning styles, four people were excluded because they fell on the line between two learning styles.

Player's completion rate was not shown to relate directly to the learning style of the participant, with roughly a similar split of completion rates between the different learning styles. 


\subsubsection{Unique Kill Methods}

Supertux came with seven unique ways to kill an enemy. Of which, no participant used more than five and everyone killed at least one. This leaves us with five groups, based on how many unique kill methods were used.

Learning Styles

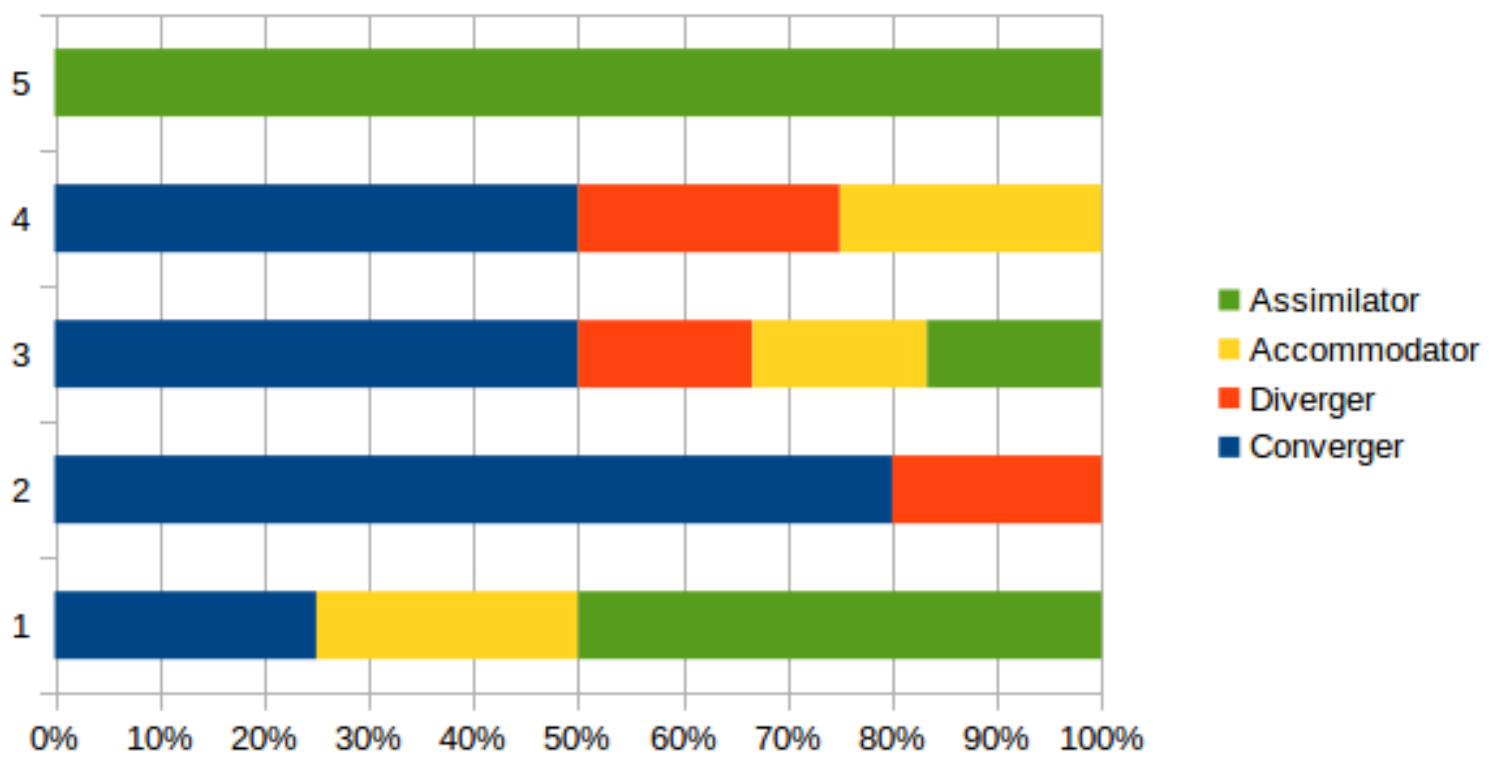

Figure 4.4: Unique Kills as Percentage

When comparing unique kills methods to learning styles, four people were excluded because they fell on the line between two learning styles.

Because the number of unique kill methods is on a gradual scale, the average amount across all members of the category yielded:

- Assimilator: 2.5 unique kill methods 
- Accommodator: 2.6667 unique kill methods

- Diverger: 3 unique kill methods

- Converger: 2.6 unique kill methods

The number of unique kill methods was not shown to relate directly to the learning style of the participant, with roughly a similar split of completion rates between the different learning styles.

\subsubsection{Other Groupings}

Other groupings we looked at did not match up well with the groupings generated from the LSI paper test. Often we were able to eliminate possible groupings from continued analysis, because the numbers simply did not form groups with characteristics similar to the groups from the LSI. For example, as none of our groupings from the paper test ended up with a $80 \% / 20 \%$ split, there is no reason to continue to evaluate groups with that split. Appendix Table C.1 shows the raw data on groupings, including those that were not selected for further analysis.

Investigation into an individual grouping was stopped as soon as it was apparent they would not match up with the paper test. This does not mean those results were not intersting. Criteria like total unique coins collected (Figure 4.5) or unique enemies killed (Figure 4.2) may not have bunched up along the same groups as learning styles, but it did show significant clustering. This could indicate potentially useful information being reflected in the metric, even if it does not correlate to the targeted learning styles. 


\subsubsection{Combinations of Groups}

Even when individual groups based on a single recorded metric from the game did not prove interesting, it is possible that taking groups together in combination might prove more fruitful. In order to evaluate if the groupings taken in combination could be used to predict learning styles, the groups were put through a classification algorithm. The participant set was split randomly into a training set and a test set, to see if the classifiers could, using the different grouping data (from Appendix Table C.1), predict the learning styles in the test set from the training set.

For this algorithm, the classifiers available in the python Natural Language Toolkit (www.nltk.org) were used. In particular, an implementation of a Naive Bayes Classifier, a Maximum Entropy Classifier, and a Decision Tree Classifier were tried. The algorithm was run several times (over multiple randomized splits of the input data).

The classifiers were unable to make accurate predictions of the players learning style based on the input groupings. The test set would generally only get a right answer $25 \%$ of the time, which is what you would expect if you were simply making a random guess between the four learning styles. Output from the classifier algorithms is in Appendix C.1

\subsection{Summation}

The analysis shows no connection between the data collected from the instrumented game and the results of the Learning Style Inventory (Paper Test). By recording these simple metrics, a relationship to the LSI is not easily detected. 


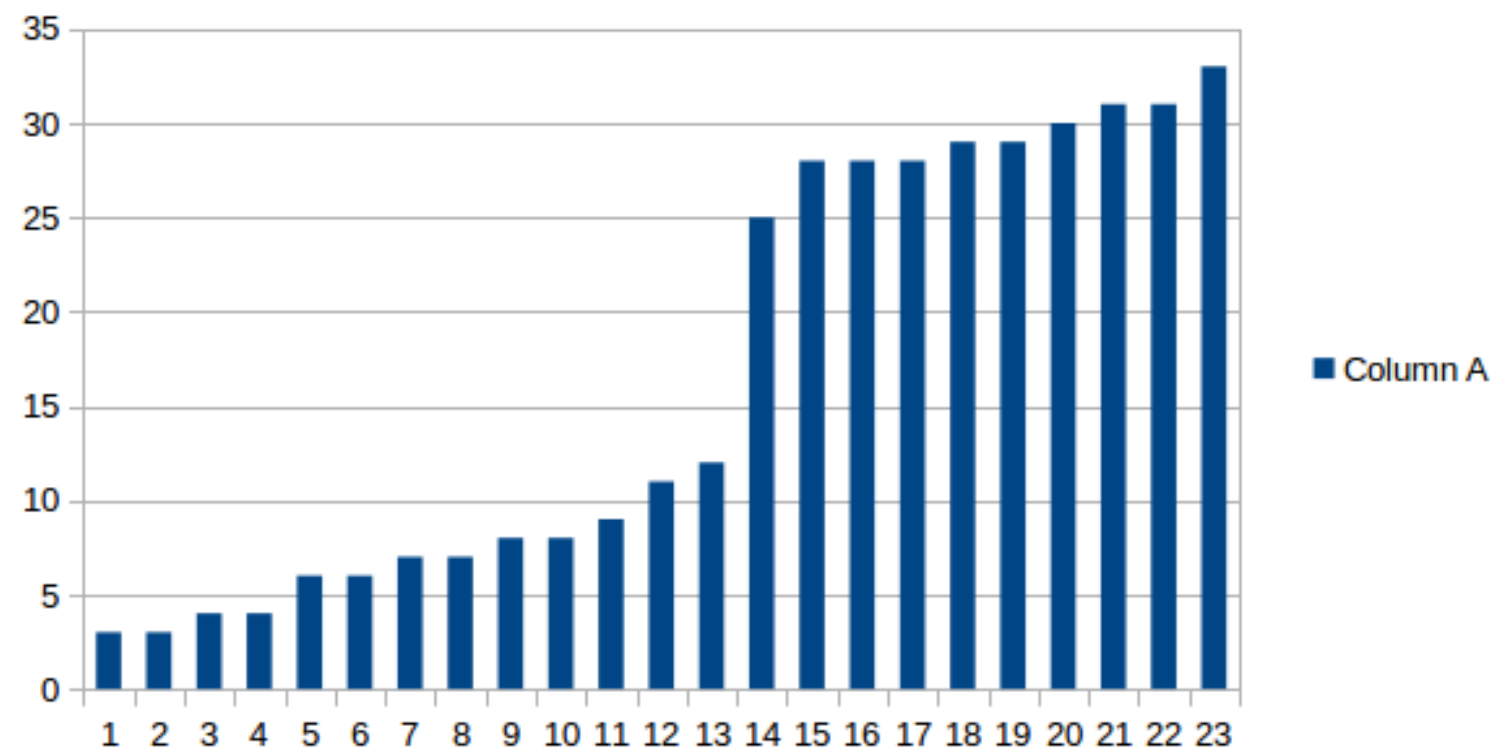

Figure 4.5: Unique Coins Collected: Participants results evaluated against the criteria of Unique Coins Collected, Sorted.

In all likelihood the Kolb Learning Style and the metrics recorded are simply not related. This could be because there is no connection between the LSI and how the game is played, or simply that the metrics recorded did not measure the learning happening in the game.

Since this was a relatively simple analysis, it is possible that deeper probing of the two data-sets might find a hidden connection. Some of the metrics collected was not categorical by nature and had to be put into groupings by a manual process (graphing out the results). This data could prove insightful with a better mechanism for classifying the data. Finally, the data could be aggregated in logical ways, such as evaluating data on a per life basis and see how things improve over time. 


\section{CHAPTER 5}

Future Work

The analysis was limited by its manual part. It is possible that in the data collected there is a connection that would have been found with better tools. A great improvement on this process would be to find a way to automatically evaluate similarities and differences between the data sets.

The simplest expansion on this work would be to choose different game variables to observe or to choose a different learning style model to compare against.

The simplest metrics to record and quantify were chosen as a starting point. More complex observations can be chosen, and they might more closely track to learning styles. For instance, a puzzle in the game could be broken down different approaches, such as a 'aggressive approach' or a 'iterative approach'. By looking at the response to the puzzles instead of just aggregated statistics, more situational context can be observed. These situational contexts are more directly related to the concept of Kolb learning styles: If someone is given a choice between watching a tutorial or jumping right into the game, that conceptually fits very well with the 'Experimentation vs Reflection' track.

Both a mechanism for dynamically determining learning styles and a way to update the game based on that information would be required in order to have a game adapt to the players learning style. Instead of focusing on determining the learning style, the second half could be addressed. In an experimental setting it is perfectly acceptable to give a paper test. 
A very simple start would be to verify that people with different learning styles do play games differently. This would be as simple as giving the test and collecting information on what types of games the players usually participate in (shooter vs puzzler). Even better would be to measure performance over selfdeclared preference, say by giving a sample of several different game types and seeing if the players differentiate themselves.

Once we know if players prefer or are better at certain types of game play, one can start looking at designing levels (in particular tutorials) to satisfy different learning types. Should this be effective, it could drive the dynamic determination of learning styles from observing game play.

Interactive environments like games would be much better served if there was an accepted learning style model that relied on observed behavior instead of self-reported questions. The LSI was not exceptional in that regard: Every learning style test we looked at to link against relies on these self-reported questions. While the simplicity of this system is desirable, it does not fit conceptually well with interactive mediums like video games. 


\title{
CHAPTER 6
}

\author{
Conclusion
}

The idea of having a video game (or any interactive medium) adapt itself to how its user learns is very appealing, but it involves knowledge that has yet to be understood. Having such an adaptive program would require both the ability to both identify a player's learning style and update based upon on it. This paper explored the concept of identifying the player's learning styles through recording their gameplay. The observations recorded did not end up lining up with learning styles, but this will hopefully provide a starting point for evaluating other recordable metrics from games against learning styles. 


\section{BIBLIOGRAPHY}

[1] K. Becker. Games and Learning Styles. In Special Session on Computer Games for Learning and Teaching, at the The IASTED International Conference on Education and Technology ICET 2005, 2005.

[2] K. Becker. The Invention of Good Games: Understanding Learning Design in Commercial Video Games. PhD thesis, University of Calgary, 2008.

[3] F. Coffield, D. Moseley, E. Hall, and K. Ecclestone. Learning styles and pedagogy in post-16 learning: A systematic and critical review. Technical report, Learning \& Skills Research Center, 2004.

[4] B. D. Coller and D. J. Shernoff. Video Game-Based Education in Mechanical Engineering: A Look at Student Engagement. International Journal of Engineering Education, 25(2):300-317, 2009.

[5] B. K. Corti. Games-based Learning; a serious business application. PIXELearning Limited, 2006.

[6] S. de Freitas and T. Mayes. Stage 2: Review of e-learning theories, frameworks and models. JISC e-Learning Models Desk Study, 2004.

[7] J. P. Gee. Learning by Design: good video games as learning machines. E-Learning, 2(1):5, 2005.

[8] M. D. Kickmeier-rust, S. Göbel, and D. Albert. 80Days: Melding Adaptive Educational Technology and Adaptive and Interactive Storytelling in Digital Educational Games. Educational Technology, 2008. 
[9] A. Y. Kolb and D. A. Kolb. The Kolb Learning Style Inventory - Version 3.1 2005 Technical Specifications. Hay Group, 2005.

[10] D. A. Kolb. Experiential Learning: Experience as the Source of Learning and Development. Prentice-Hall, Englewood Cliffs, NJ, 1984.

[11] W. L. Leite, M. Svinicki, and Y. Shi. Attempted Validation of the Scores of the VARK: Learning Styles Inventory With Multitrait-Multimethod Confirmatory Factor Analysis Models. Educational and Psychological Measurement, 70(2):323-339, Apr. 2010.

[12] T. V. Malone. What Makes Things Fun to Learn? Heuristics for Designing Instructional Computer Games. Proceedings of the 3rd ACM SIGSMALL symposium and the first SIGPC symposium on Small systems, 162, 1980.

[13] H. Pashler, M. McDaniel, D. Rohrer, and R. Bjork. Learning styles concepts and evidence. Psychological science in the public interest, 9(3):105-119, 2008.

[14] N. Peirce, O. Conlan, and V. Wade. Adaptive Educational Games: Providing Non-invasive Personalised Learning Experiences. 2008 Second IEEE International Conference on Digital Game and Intelligent Toy Enhanced Learning, pages 28-35, 2008.

[15] M. Prensky. Digital game-based learning. Computers in Entertainment, 1(1):21, Oct. 2003.

[16] S. Thomas. Pervasive learning games: Explorations of hybrid educational gamescapes. Simulation \& Gaming, 37(1):41-55, Mar. 2006.

[17] X. Zhao. Adaptive Support For Student Learning in Educational Games. PhD thesis, The University of British Columbia, 2002. 
APPENDICES 


\section{APPENDIX A}

Experiment Design

Table A.1: List of Recorded Events

\begin{tabular}{|c|c|c|}
\hline Event Name & Data Gathered & Description \\
\hline Starting Level & Start Position & When the level is first started \\
\hline Direction Change & Direction Changed To & $\begin{array}{l}\text { The avatar's direction of } \\
\text { movement is either to the left } \\
\text { or right. Each change is } \\
\text { recorded. }\end{array}$ \\
\hline Player Hurt & $\begin{array}{l}\text { Bad Guy Name, Bad } \\
\text { Guy Starting Location, }\end{array}$ & $\begin{array}{c}\text { A bad guy can either kill or } \\
\text { damage the avatar. Each hit is } \\
\text { recorded. }\end{array}$ \\
\hline Player Killed & Death Cause & $\begin{array}{l}\text { If the bad guy succeeded in } \\
\text { killing the avatar, it is an } \\
\text { additional recorded line. }\end{array}$ \\
\hline Restarting Level & Start Position & When the level is restarted \\
\hline Block Hit & $\begin{array}{c}\text { Block Starting } \\
\text { Location, Block Type }\end{array}$ & $\begin{array}{l}\text { The avatar can interact with } \\
\text { certain blocks if hit from below. } \\
\text { This records the hit, and if it is } \\
\text { a bonus block, what item was } \\
\text { in the block. }\end{array}$ \\
\hline
\end{tabular}




\begin{tabular}{|c|c|c|}
\hline $\begin{array}{c}\text { Bad Guy Killed By } \\
\text { Player }\end{array}$ & $\begin{array}{c}\text { Bad Guy start location, } \\
\text { bad guy type, Method } \\
\text { of Kill, }\end{array}$ & $\begin{array}{c}\text { When the avatar kills a bad } \\
\text { guy }\end{array}$ \\
\hline Secret Area & $\begin{array}{c}\text { There is one secret area in the } \\
\text { level, a line is recorded if and } \\
\text { when the avatar first enters the } \\
\text { area }\end{array}$ \\
\hline Save Point & $\begin{array}{c}\text { There is one save point } \\
\text { halfway through the level. A } \\
\text { line is recorded when the } \\
\text { avatar interacts with the safe } \\
\text { point. }\end{array}$ \\
\hline Upgrade Collected & Upgrade Start Location & $\begin{array}{c}\text { There are several types of } \\
\text { upgrades the avatar can } \\
\text { interact by walking over them. } \\
\text { A line is recorded when the } \\
\text { avatar interacts with the }\end{array}$ \\
upgrade.
\end{tabular}




\section{APPENDIX B}

Experiment Results

B.1 LSI (Paper Test)

Table B.1: Learning Style Test Results

\begin{tabular}{lllllll}
\hline Participant & CE & RO & AC & AE & CE - AC & RO - AE \\
\hline 1 & 12 & 16 & 23 & 14 & -11 & 2 \\
\hline 2 & 14 & 14 & 18 & 18 & -4 & -4 \\
\hline 3 & 10 & 13 & 23 & 17 & -13 & -4 \\
\hline 4 & 16 & 15 & 10 & 12 & 6 & 3 \\
\hline 5 & 12 & 15 & 23 & 15 & -11 & 0 \\
\hline 6 & 10 & 12 & 20 & 15 & -10 & -3 \\
\hline 7 & 8 & 16 & 22 & 14 & -14 & 2 \\
\hline 8 & 14 & 10 & 21 & 20 & -7 & -10 \\
\hline 9 & 9 & 11 & 23 & 17 & -14 & -6 \\
\hline 10 & 13 & 16 & 13 & 21 & 0 & -5 \\
\hline 11 & 14 & 17 & 17 & 17 & -3 & 0 \\
\hline 12 & 16 & 15 & 20 & 8 & -4 & 7 \\
\hline 13 & 16 & 15 & 17 & 16 & -1 & -1 \\
\hline
\end{tabular}




\begin{tabular}{lllllll}
14 & 12 & 15 & 18 & 18 & -6 & -3 \\
\hline 15 & 14 & 14 & 12 & 17 & 2 & -3 \\
\hline 16 & 16 & 14 & 14 & 18 & 2 & -4 \\
\hline 17 & 12 & 8 & 15 & 22 & -3 & -14 \\
\hline 18 & 13 & 20 & 19 & 13 & -6 & 7 \\
\hline 19 & 21 & 14 & 13 & 13 & 8 & 1 \\
\hline 20 & 15 & 12 & 16 & 21 & -1 & -9 \\
\hline 21 & 19 & 10 & 8 & 14 & 11 & -4 \\
\hline 23 & 18 & 18 & 18 & 15 & 0 & 3 \\
\hline
\end{tabular}

\section{B.2 Game Test Results}

Due to the size and nature of the raw data, duplication of the complete data set is not included. The raw data set contains two files per player. The first is the set of raw events that were recorded (Enumerated in Appendix Table A.1). The second file contains the output of a simple analysis/aggregation program that grouped the events by a variaty of criterial (such as life or enemy type).

\section{B.2.1 Sample Raw Event Data}

EVENT_LOG|O|Starting Run Wed Dec 4 12:22:43 2013

EVENT_LOG|O|Starting Level at pos|96 
STEP_LOG|3 | playerX?96| playerY?576| playerJumping ?0|

playerDirection? right | playerCoins? $100 \mid$ big? 0 |

STEP_LOG|8| playerX?746.837|playerY ?577.198|playerJumping

?0| playerDirection? right | playerCoins?100|big?0|

EVENT_LOG|8|Changed Direction to left

EVENT_LOG|8|Bad Guy Hurt Player|1131|571|images/creatures

/ snowball / snowball. sprite

EVENT_LOG|8|Player Killed by wound

EVENT_LOG|11|Restarting Level|96

STEP_LOG|13| playerX ?275.404|playerY ?577.198|playerJumping

?0|playerDirection? right | playerCoins?100|big?0|

EVENT_LOG|16|Player Killed Bad Guy By Squishing|1131|571| images/creatures/snowball/snowball. sprite

EVENT_LOG|17|Player Killed Bad Guy By Squishing|1213|571|

images/creatures/snowball/snowball . sprite

STEP_LOG|18|playerX?707.448|playerY?520.673|playerJumping

?0| playerDirection?right | playerCoins?100|big?0|

This is a short sample of output recorded during game play. The columns are seperated by the character 'l'.

The first column is either EVENT_LOG (an event happened that caused the line to be logged) or STEP_LOG (A line that is logged periodically).

The second column is time (in seconds) from when the run began. 
With a step log, the remaining columns are printed in a known fashion and are the same for every step log event. With the event log, the third column is an event name, followed by colums that have data specific to that event name.

\section{B.2.2 Sample Analysis/Aggregated output}

A small program was used to parse the raw data into more useable aggregated data.

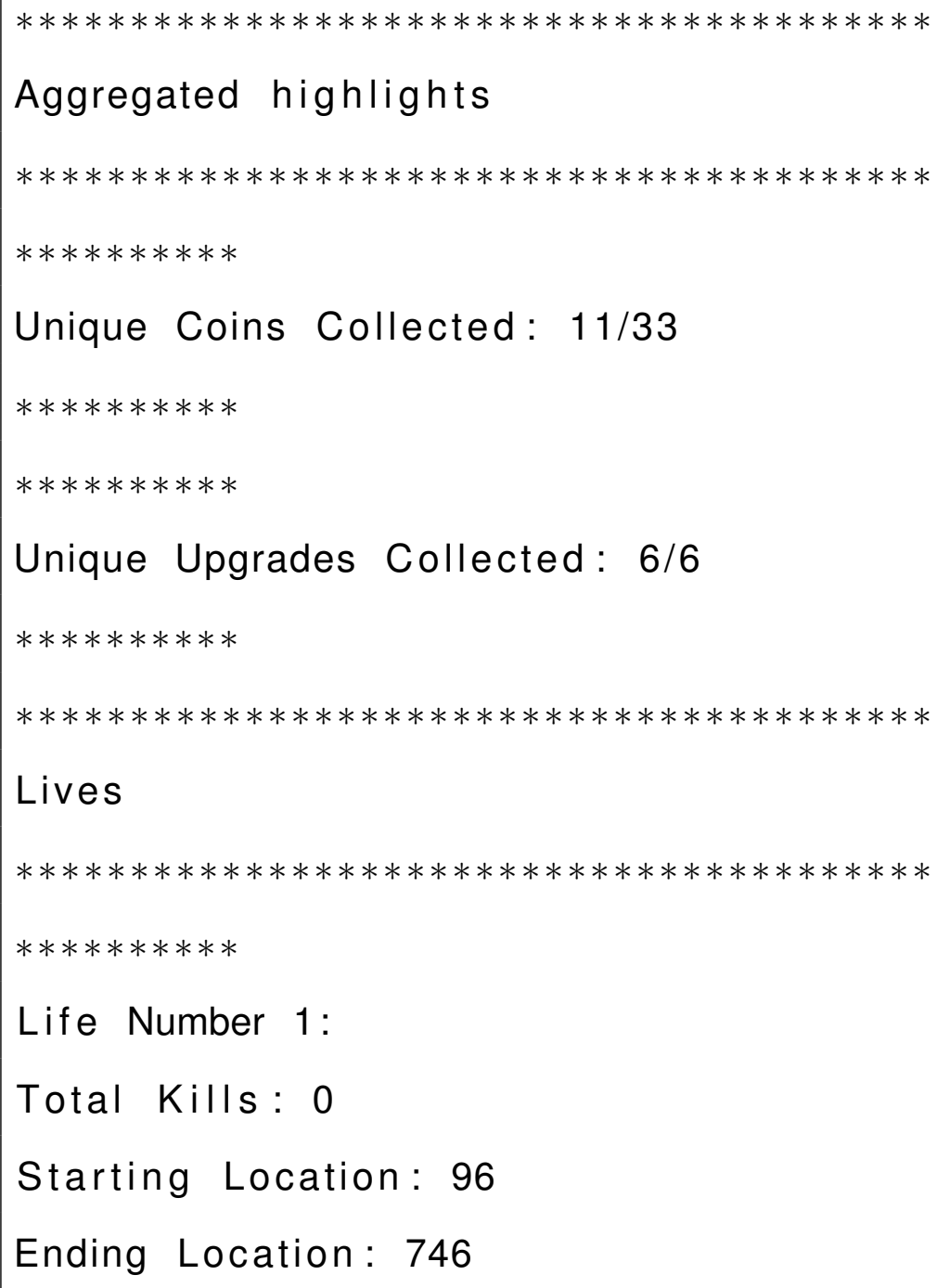




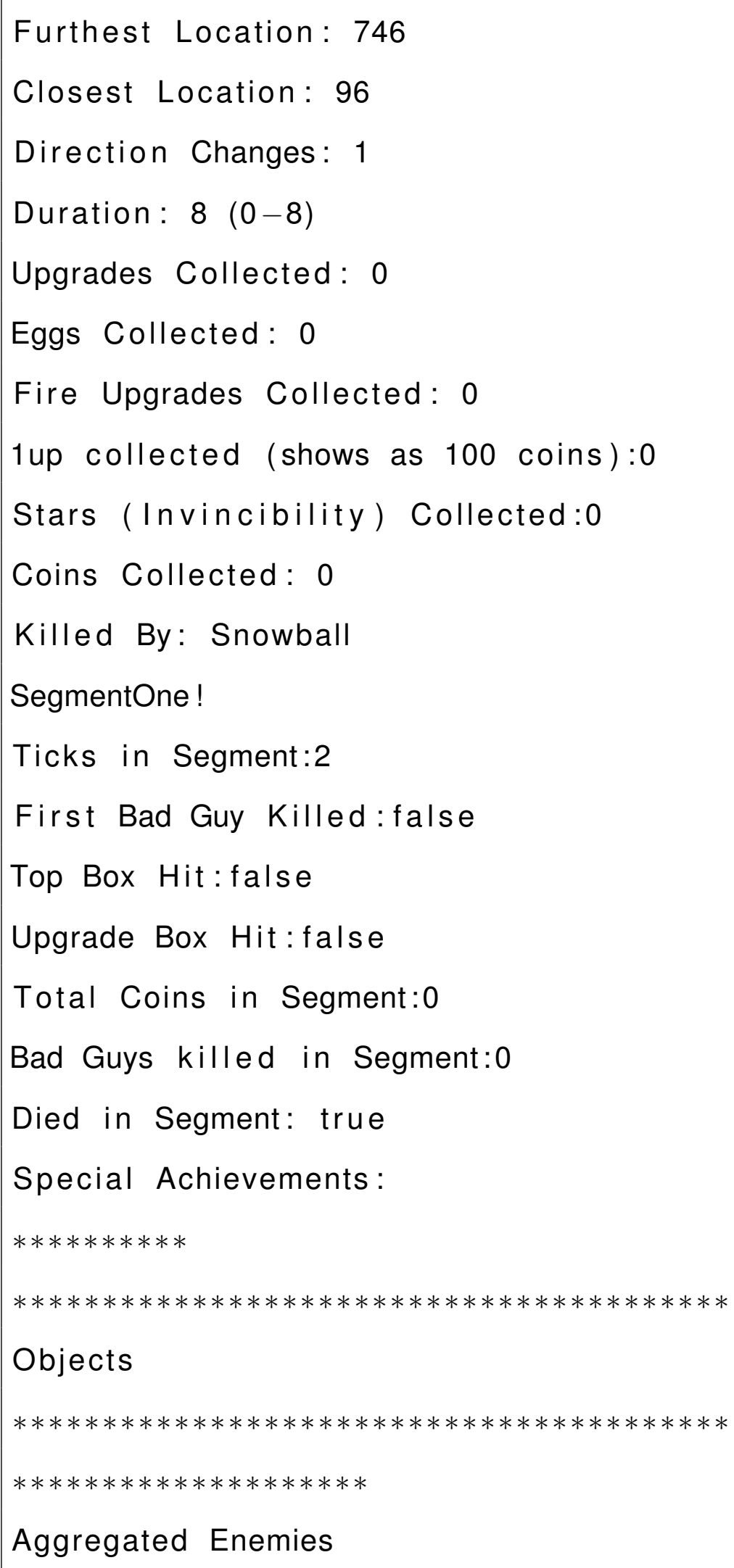




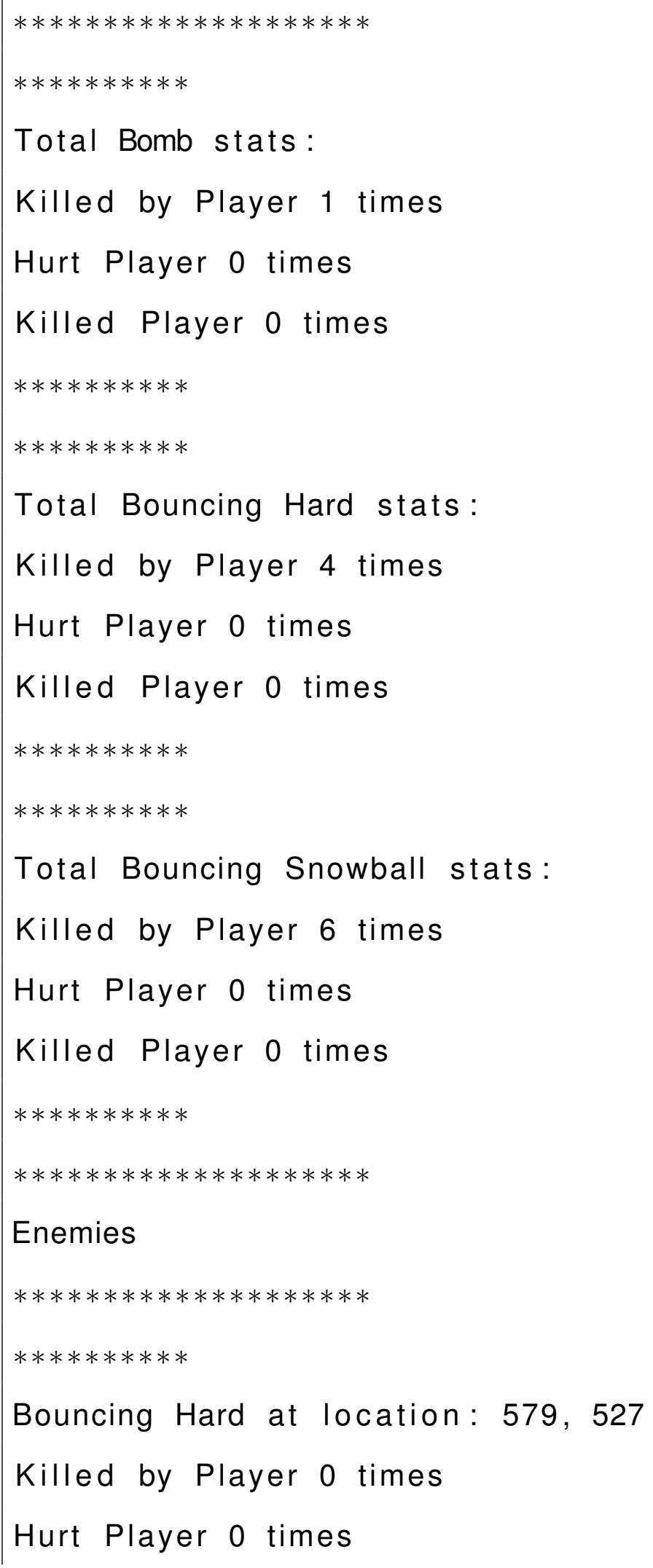

Bouncing Hard at location: 579, 527

Killed by Player 0 times

Hurt Player 0 times 


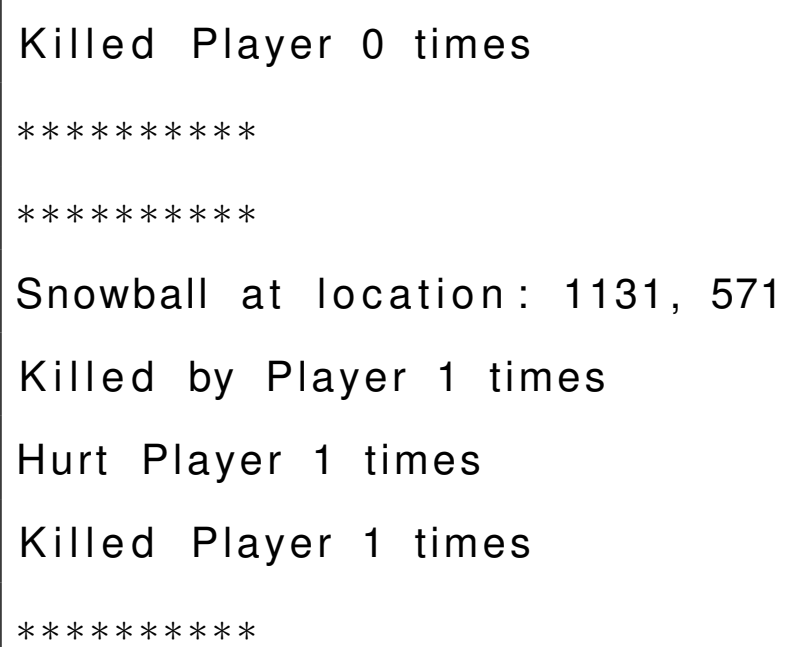

This is a simplified (only a few items per section) example of the aggregated file. The aggregated file attempted to organize the data in sets that make more sense than a constant stream. The following was reported:

1. Aggregated Highlights: Either Totaled (Total number of times something happened), or Aggregated (Results Aggregated so that duplication across lives are ignored.)

(a) "Total Duration": Totaled; Length of Play (in seconds).

(b) "Killed Enemies in x/7 Different Ways": Aggregated; Of the seven unique ways in the game to kill an enemy, how many did the player manage to complete?

(c) "Unique Coins Collected x/33": Aggregated; Of the 33 coins in the level, how many did the player find?

(d) "Unique Upgrades Collected x/6": Aggregated; Of the 6 types of upgrades, how many did the player find? 
(e) "Unique Enemies Killed x/50": Aggregated; Of the fifty enemies in the level, how many did the player manage to kill?

(f) "x eggs collected": Totaled; How many eggs did the player collect over all runs?

(g) "x Fire Upgrades collected": Totaled; How many fire upgrades (allows player to shoot fireballs) did the player collect over all runs?

(h) "x oneup (100 coins) collected": Totaled, How many times did the player collect the one-up icon (shows as 100 coins in the $\mathrm{UI}$ )?

(i) "x Star (Invincible) collected ": Totaled, How many times did the player collect the star upgrade?

(j) "Total Deaths": Totaled, How many times did the player die?

(k) "Deaths By Map": Totaled, How many times did the player die from the map (not an enemy, such as a pit)?

(I) "x direction changes": Totaled, How many times did the player change the direction they were facing?

2. Lives: For each life the player had, the following is recorded

(a) Life Number: An incrementing number starting from 1

(b) Starting Location: The location the player started, either map start (96) or the safepoint (8480)

(c) Ending Location: Where the player was when the life ended.

(d) Furthest Location: The furthest to the right the player had gotten on the current life.

(e) Closest Location: The furthest to the left the player had gotten on the current life. 
(f) Direction Changes: The number of direction changes on this life.

(g) Duration: How long this life took (endTime - startTime)

(h) Upgrades Collected: Total Upgrades Collected, Plus a breakdown of each upgrade type.

(i) Coins Collected: Number of Coins collected on the current life.

(j) Killed By: What enemy killed the player. "Map Death" is a death not caused by an enemy, such as a pit, while "None" means the player did not die (Finished Level/Quit).

(k) SegmentOne!: This is a short segment at the beginning of the game that comprises of the first five bad guys, and a triangle of coin boxes (four on the bottom row, two on the middle row, one on the top row). This segment is called out to investigate if looking at short challenges in the game reviels more than looking at whole level statistics (Location 0 - Location xxxx).

i. Ticks in Segment: The number of step events (ticks) that happened in the segment

ii. First Bad Guy Killed: If the player managed to kill the first bad guy. A rather contrived set of steps is needed to kill this bad guy, so it generally will not happen

iii. Top Box Hit: The top box of the triangle was hit. This is also not a easy task, and would take many tries.

iv. Upgrade Box Hit: One of the lower boxes contains an upgrade, this says if it is hit or not.

v. Total Coins in Segment: How many coins were collected from the segment. The total possible is 6 . 
vi. Bad Guys killed in Segment: Total bad guys killed in segment. Total Possible is 5 ?

vii. Died in Segment: If the player died in the segment

(I) Special Notes: These are special flags that were not worth including as their own line item above. Flags are only printed if they are achieved. Possible Flags are Below
i. Save Point Reached
ii. Secret Area Found

3. Objects (Listing of every object in the game and how many times the player interacted with it)

(a) Aggregated Enemies: Enemy Statistics aggregated by Enemy Type. Each enemy type has the following

i. Killed by player: How many times this type of enemy was killed by the player

ii. Hurt Player: How many times this type of enemy hurt the player

iii. Killed Player: How many times this type of enemy killed the player (would also hurt).

(b) Enemies: For each enemy in the game (50 total), the following is printed

i. Location of Enemy

ii. Killed by player: How many times this enemy was killed by the player

iii. Hurt Player: How many times this enemy hurt the player 
iv. Killed Player: How many times this enemy killed the player (would also hurt)

(c) Collectables: Items that can be collected in the game (such as coins) For each collectable, the following is recorded:
i. Location of Collectable
ii. Times Collected

4. At the end of the file, the same data as above is printed in CSV form. 
B.3 Aggregated Data

Table B.2: Aggregated Data

AssimulatorsConvergers Divergers Accommodators

(10)

(3)

(6)

\begin{tabular}{lllll}
\hline Life Number & 15.3 & 6.8 & 14.3 & 12.1 \\
Total Kills & 1.9 & 5.1 & 5.6 & 4.2 \\
Starting Location & 3843.4 & 2308.0 & 1987.5 & 2713.0 \\
Ending Location & 4568.2 & 6744.7 & 5668.4 & 5660.4 \\
Furthest Location & 5417.9 & 7078.0 & 5887.6 & 6127.8 \\
Closest Location & 3803.5 & 2270.0 & 1987.4 & 2687.0 \\
Direction Changes & 11.8 & 36.8 & 29.5 & 26.1 \\
Duration & 34.4 & 55.2 & 66.4 & 52.0 \\
Total Upgrades Collected & 0.4 & 1.0 & 1.1 & 0.8 \\
Eggs Collected & 0.3 & 0.6 & 0.9 & 0.6 \\
Fire Upgrade Collected & 0.0 & 0.3 & 0.0 & 0.1 \\
1up Collected & 0.0 & 0.0 & 0.1 & 12.1 \\
Stars Collected & 0.0 & 0.1 & 0.1 & 2.5 \\
Coins Collected & 2.2 & 0.1 & 0.1 & 3.8
\end{tabular}




\section{APPENDIX C}

Analysis

Table C.1: Participant Groupings

\begin{tabular}{|c|c|c|c|c|c|c|c|c|}
\hline 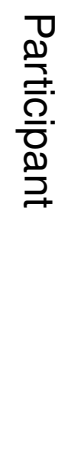 & 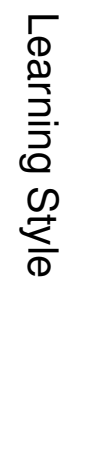 & $\begin{array}{l}\text { ᄋ } \\
\frac{3}{3} \\
\frac{0}{D} \\
\frac{1}{\overline{0}}\end{array}$ & 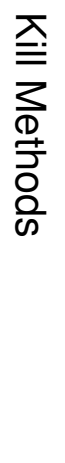 & 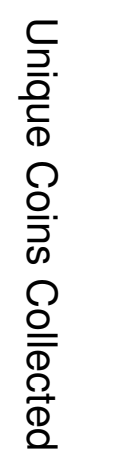 & 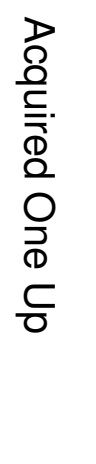 & 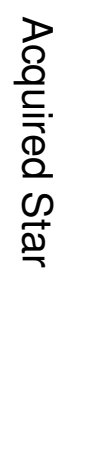 & 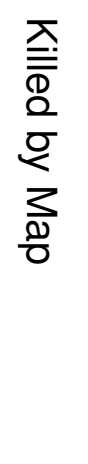 & 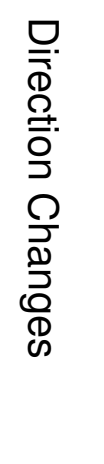 \\
\hline 1 & AS & $100 \%$ & 3 & $6-12$ & Yes & Yes & 0 & $\begin{array}{l}57- \\
140\end{array}$ \\
\hline 2 & $\mathrm{CO}$ & $100 \%$ & 4 & $25-33$ & No & Yes & $1-4$ & $\begin{array}{l}370- \\
462\end{array}$ \\
\hline 3 & $\mathrm{CO}$ & $100 \%$ & 4 & $25-33$ & No & Yes & $1-4$ & $\begin{array}{l}57- \\
140\end{array}$ \\
\hline 4 & DI & $>50 \%$ & 3 & $25-33$ & No & No & $5+$ & $\begin{array}{l}370- \\
462\end{array}$ \\
\hline 5 & $\mathrm{~N} / \mathrm{A}$ & $100 \%$ & 3 & $6-12$ & No & No & 0 & $\begin{array}{l}57- \\
140\end{array}$ \\
\hline 6 & $\mathrm{CO}$ & $100 \%$ & 2 & $6-12$ & No & No & 0 & $\begin{array}{l}370- \\
462\end{array}$ \\
\hline
\end{tabular}




\begin{tabular}{|c|c|c|c|c|c|c|c|c|}
\hline 7 & AS & $<50 \%$ & 1 & $6-12$ & No & No & 0 & $\begin{array}{l}180- \\
295\end{array}$ \\
\hline 8 & $\mathrm{CO}$ & $>50 \%$ & 3 & $25-33$ & No & No & 0 & $\begin{array}{l}57- \\
140\end{array}$ \\
\hline 9 & $\mathrm{CO}$ & $<50 \%$ & 2 & $6-12$ & No & No & 0 & $\begin{array}{l}57- \\
140\end{array}$ \\
\hline 10 & $\mathrm{CO}$ & $<50 \%$ & 1 & $6-12$ & No & No & 0 & $\begin{array}{l}57- \\
140\end{array}$ \\
\hline 11 & $\mathrm{~N} / \mathrm{A}$ & $100 \%$ & 4 & $25-33$ & No & Yes & $5+$ & $\begin{array}{l}180- \\
295\end{array}$ \\
\hline 12 & AS & $100 \%$ & 5 & $25-33$ & Yes & Yes & $5+$ & $\begin{array}{l}670- \\
745\end{array}$ \\
\hline 13 & $\mathrm{CO}$ & $<50 \%$ & 2 & $3-4$ & No & No & 0 & $2-22$ \\
\hline 14 & $\mathrm{CO}$ & $>50 \%$ & 3 & $6-12$ & Yes & Yes & $5+$ & $\begin{array}{l}370- \\
462\end{array}$ \\
\hline 15 & $A C$ & $>50 \%$ & 3 & $25-33$ & Yes & No & $1-4$ & $\begin{array}{l}180- \\
295\end{array}$ \\
\hline 16 & $A C$ & $<50 \%$ & 1 & $3-4$ & No & No & 0 & $2-22$ \\
\hline 17 & $\mathrm{CO}$ & $100 \%$ & 3 & $25-33$ & No & No & 0 & $\begin{array}{l}57- \\
140\end{array}$ \\
\hline 18 & AS & $<50 \%$ & 1 & $3-4$ & No & No & 0 & $2-22$ \\
\hline 19 & DI & $100 \%$ & 4 & $6-12$ & Yes & Yes & 0 & $\begin{array}{l}180- \\
295\end{array}$ \\
\hline 20 & $\mathrm{CO}$ & $100 \%$ & 2 & $25-33$ & No & No & $1-4$ & $\begin{array}{l}180- \\
295\end{array}$ \\
\hline
\end{tabular}




\begin{tabular}{|l|l|l|l|l|l|l|l|l|}
\hline 21 & AC & $100 \%$ & 4 & $25-33$ & No & No & $5+$ & $\begin{array}{l}670- \\
745\end{array}$ \\
\hline 22 & N/A & $<50 \%$ & 2 & $3-4$ & No & No & 0 & $2-22$ \\
\hline 23 & DI & $<50 \%$ & 2 & $6-12$ & No & No & 0 & $\begin{array}{l}180- \\
295\end{array}$ \\
\hline
\end{tabular}

C.1 Classifier Output

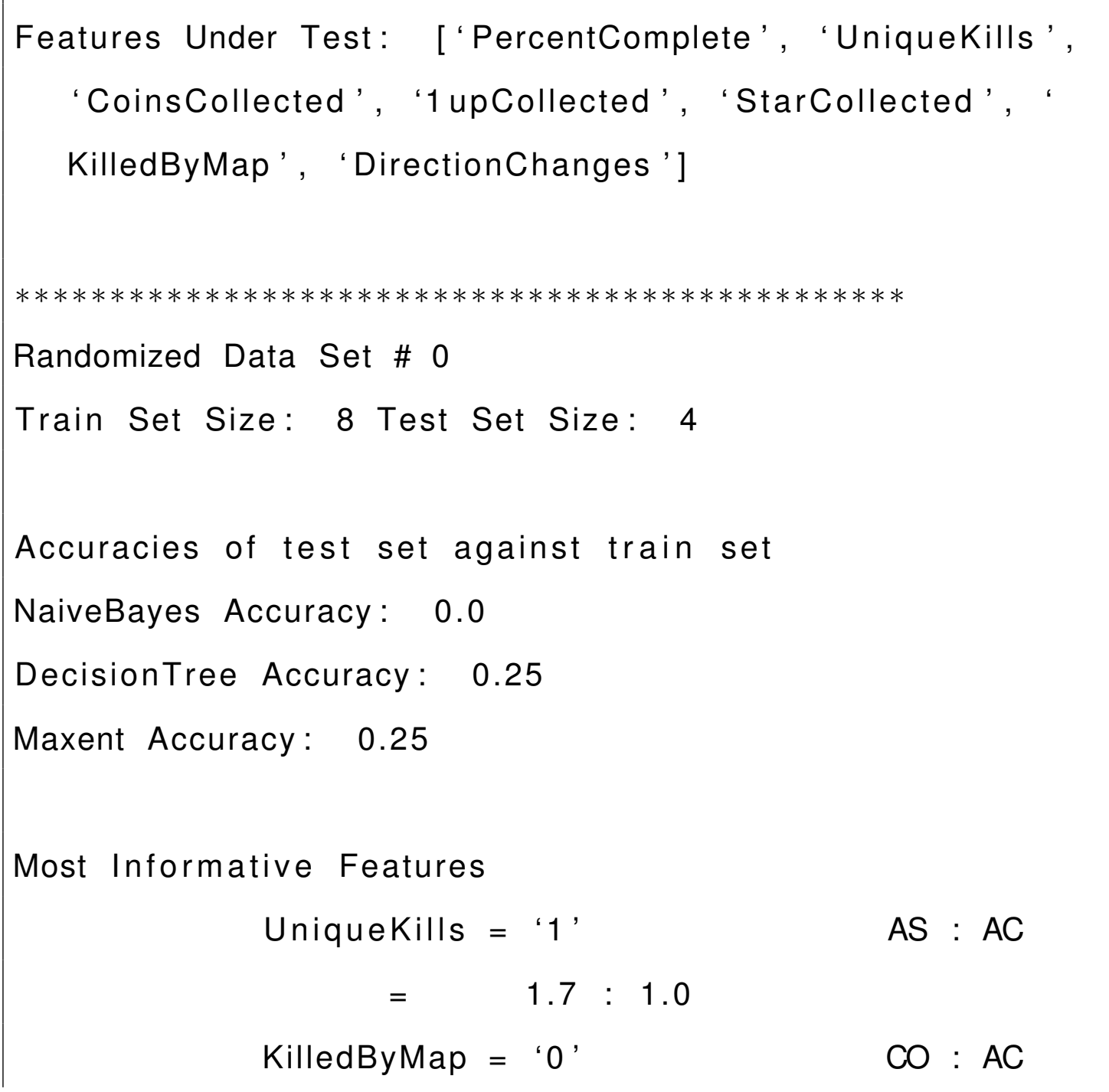




$$
\begin{array}{ccc}
= & 1.7: 1.0 & \\
\text { 1 upCollected } & =\text { 'No' } & \text { DI }: A C \\
= & 1.7: 1.0 &
\end{array}
$$

NaiveBayes: None

4.625 UniqueKills =='2' and label is ' $\mathrm{CO}$ '

4.027 UniqueKills =='2' and label is 'DI'

3.559 UniqueKills =='1' and label is 'AS'

Maxent: None

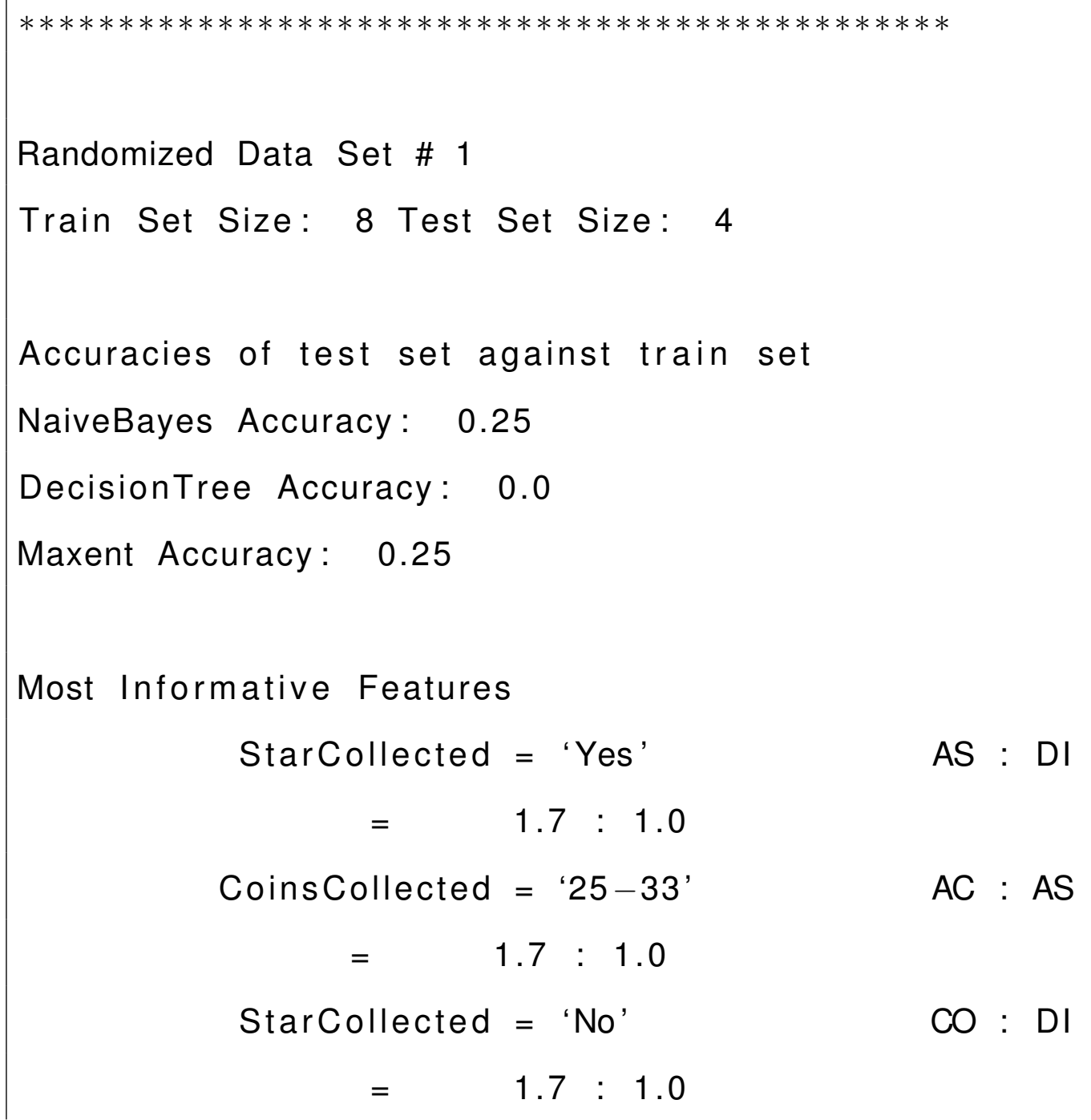




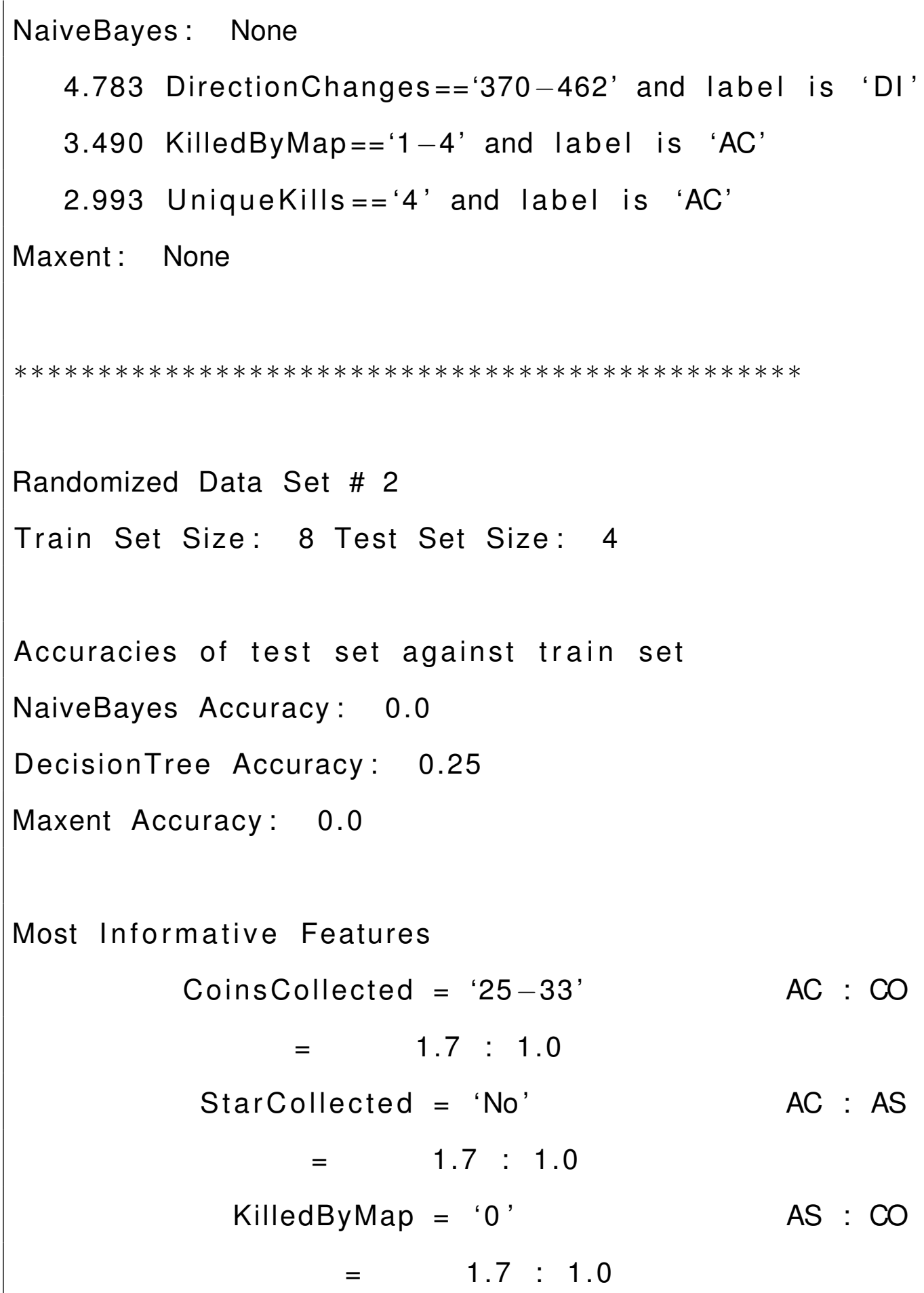

NaiveBayes: None

4.720 DirectionChanges $==$ ' $57-140$ ' and label is ' $C O$ ' 3.986 DirectionChanges $==670-745$ ' and label is 'AC' 
3.758 UniqueKills $==$ ' 3 ' and label is 'AS'

Maxent: None

$* * * * * * * * * * * * * * * * * * * * * * * * * * * * * * * * * * * * * * * * * * * * * * *$

Randomized Data Set \# 3

Train Set Size: 8 Test Set Size: 4

Accuracies of test set against train set

NaiveBayes Accuracy: 0.0

DecisionTree Accuracy: 0.25

Maxent Accuracy: 0.0

Most Informative Features

$$
\begin{aligned}
& 1 \text { upCollected }=\text { 'No' } \quad \mathrm{CO}: \text { AS } \\
& =\quad 1.7: 1.0 \\
& \text { StarCollected }=\text { 'No' } \quad \text { CO : AS } \\
& =\quad 1.7: 1.0 \\
& \text { UniqueKills }=\text { ' } 1 \text { ' AC : AS } \\
& =1.0: 1.0
\end{aligned}
$$

NaiveBayes: None

3.708 DirectionChanges $==370-462$ ' and label is ' $\mathrm{DI}$ '

3.638 UniqueKills $==$ '4' and label is 'DI'

3.439 Coins Collected $==$ ' $3-4$ ' and label is 'AC'

Maxent: None 


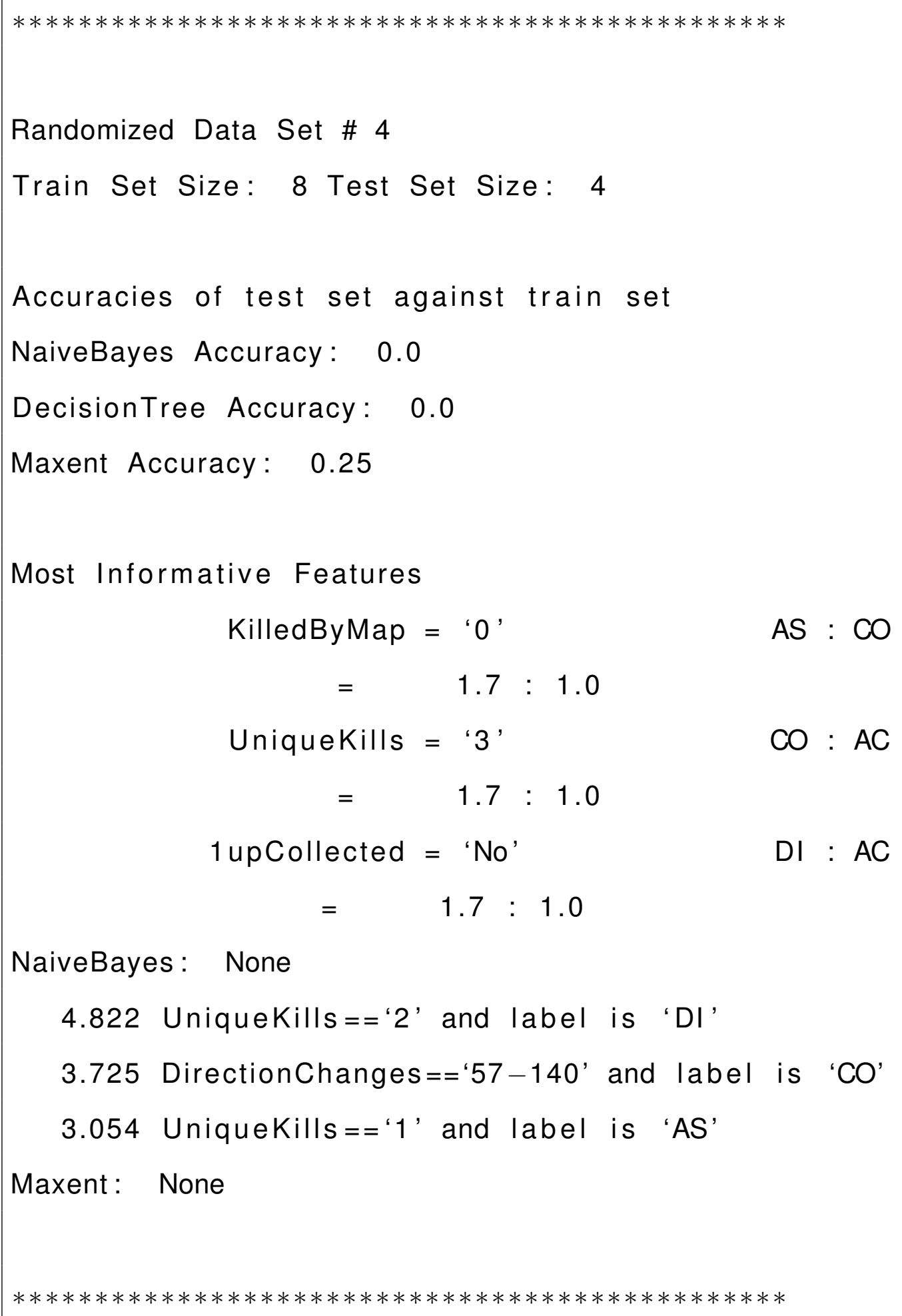

NaiveBayes: None

4.822 UniqueKills $==$ ' 2 ' and label is ' $\mathrm{Dl}$ '

3.725 DirectionChanges $==$ ' $57-140$ ' and label is 'CO'

3.054 UniqueKills $==$ ' 1 ' and label is 'AS' Maxent: None 